\title{
Pro-aggregant Tau impairs mossy fiber plasticity due to structural changes and $\mathrm{Ca}^{++}$dysregulation
}

\author{
Jochen Martin Decker ${ }^{1 \dagger}$, Lars Krüger ${ }^{1 \dagger}$, Astrid Sydow ${ }^{1}$, Shanting Zhao ${ }^{4}$, Michael Frotscher ${ }^{4}$, \\ Eckhard Mandelkow ${ }^{1,2,3}$ and Eva-Maria Mandelkow ${ }^{1,2,3^{*}}$
}

\begin{abstract}
Introduction: We used an inducible mouse model expressing the Tau repeat domain with the pro-aggregant mutation $\Delta$ K280 to analyze presynaptic Tau pathology in the hippocampus.

Results: Expression of pro-aggregant Tau ${ }^{\mathrm{RD} \Delta}$ leads to phosphorylation, aggregation and missorting of Tau in area CA3. To test presynaptic pathophysiology we used electrophysiology in the mossy fiber tract. Synaptic transmission was severely disturbed in pro-aggregant Tau ${ }^{\mathrm{RD} \Delta}$ and Tau-knockout mice. Long-term depression of the mossy fiber tract failed in pro-aggregant Tau ${ }^{\mathrm{RD} \Delta}$ mice. We observed an increase in bouton size, but a decline in numbers and presynaptic markers. Both pre-and postsynaptic structural deficits are preventable by inhibition of $\operatorname{Tau}^{\mathrm{RD} \Delta}$ aggregation. Calcium imaging revealed progressive calcium dysregulation in boutons of pro-aggregant Tau ${ }^{\mathrm{RD} \Delta}$ mice. In N2a cells we observed this even in cells without tangle load, whilst in primary hippocampal neurons transient Tau ${ }^{\mathrm{RD} \Delta}$ expression alone caused similar $\mathrm{Ca}^{++}$dysregulation. Ultrastructural analysis revealed a severe depletion of synaptic vesicles pool in accordance with synaptic transmission impairments.
\end{abstract}

Conclusions: We conclude that oligomer formation by Tau ${ }^{\mathrm{RD} \Delta}$ causes pre- and postsynaptic structural deterioration and $\mathrm{Ca}^{++}$dysregulation which leads to synaptic plasticity deficits.

Keywords: Calcium dysregulation, Long-term depression, Mossy fiber pathway, Presynapse, Tau

\section{Introduction}

Several neurodegenerative disorders are characterized by pathological aggregation of the axonal protein Tau into "neurofibrillary tangles" classifying them as tauopathies [1]. The clinical signs of various tauopathies including Alzheimer disease (AD) and frontotemporal dementia with Parkinsonism linked to chromosome 17 (FTDP-17) correlate well with the anatomical localization of Tau aggregates in the brain [2]. Especially in AD, a correlation of hyperphosphorylated, aggregated Tau distribution and cognitive impairment is evident [3]. So far, most electrophysiological studies investigated Tau-related postsynaptic changes in area CA1 of the hippocampus [4-6]. However, it became increasingly obvious from animal models expressing mutant Tau that Tau pathology

\footnotetext{
*Correspondence: eva.mandelkow@dzne.de

${ }^{\dagger}$ Equal contributors

${ }^{1}$ German Center for Neurodegenerative Diseases (DZNE), Ludwig-Erhard-Allee 2, 53175 Bonn, Germany

${ }^{2}$ Caesar Research Center, Ludwig-Erhard-Allee 2, 53175 Bonn, Germany

Full list of author information is available at the end of the article
}

appears prominently in the stratum lucidum (s.l.) of area CA3 where axons of granule cells form the mossy fiber path [7-9]. In transgenic mice expressing the aggregationprone human Tau repeat domain with the FTDP-17 mutation $\Delta \mathrm{K} 280$ (termed pro-aggregant $\mathrm{Tau}^{\mathrm{RD} \Delta}$ ), exogenous mutant Tau co-aggregates with endogenous mouse Tau to assemble into neurofibrillary tangles in area CA3, whereas mice expressing anti-aggregant Tau ( $\mathrm{Tau}_{\mathrm{RD}} \Delta \mathrm{K} 280 \mathrm{PP}$, termed $T a u^{R D} \Delta \mathrm{PP}$, containing two additional prolines inhibiting ß-structure) do not show pathology [8]. In Alzheimer disease pathological Tau is found within the hippocampal formation [10]. Recent observations on human AD brains though demonstrated abnormal Tau phosphorylation in thorny excrescences, the specialized spine structures characteristic for CA3 pyramidal neurons which constitute the postsynaptic target of mossy fiber boutons [11]. The density of thorny excrescences was decreased whereas their size was increased during the course of AD [12]. Moreover, immunoreactivity with AD-diagnostic antibodies PHF1, Alz50, and TG3 [13-15] were found in DG granule 
cells of $\mathrm{AD}$ patients, pointing to a clinical relevance of the mossy fiber pathway to Tau-related disease progression.

In hibernating ground squirrels, Tau becomes highly phosphorylated and missorted from its normal axonal localization into the somatodendritic compartment, which leads to the retraction of mossy fibers from CA3 postsynapses [16]. This process is reversible and suggests a physiological role of Tau in mossy fiber plasticity. In addition, Tau plays an important role in mossy fiber reorganization during development [17], and Tau is involved in the pathological sprouting of mossy fibers induced by kainate injection to generate epileptic seizures [18].

Thorny excrescences are innervated by "giant" mossy fiber boutons, which are characterized by their low basal transmitter release probability [19]. This is maintained by the action of presynaptic adenosine (A1) receptors [20] and group II metabotropic glutamate receptors (mGluRII) [21]. Long term depression (LTD) at the mossy fiber-CA3 synapse is expressed presynaptically as a reduction in neurotransmitter release [22] and depends on an activity-dependent rise in intracellular calcium $\left(\mathrm{Ca}^{++}\right)$concentrations [23].

In the present study we wanted to clarify to what extent pro-aggregant human $\mathrm{Tau}^{\mathrm{RD} \Delta}$ influences presynaptic plasticity in the hippocampus. For this purpose, we performed functional and morphological analyses of the mossy fiber synapse in Tau aggregation models and Tau knockout (TKO) mice. We found that aggregating Tau causes pre- and postsynaptic morphological changes at the mossy fiber-CA3 synapse and an impairment of LTD in pro-aggregant $\mathrm{Tau}{ }^{\mathrm{RD} \Delta}$. Endogenous Tau was necessary for basal synaptic transmission at that synapse. In vitro $\mathrm{Ca}^{++}$imaging studies with organotypic hippocampal slices, primary hippocampal neurons and N2a cells expressing pro-aggregant Tau ${ }^{\mathrm{RD} \Delta}$ demonstrated dysregulation of neuronal calcium influx as a possible basis for plasticity impairment. Structural synaptic changes could be prevented partially by the inhibition of Tau aggregation.

\section{Materials and methods}

\section{Generation of $\mathrm{Tau}^{\mathrm{RD} \Delta}$ transgenic mice}

Regulatable transgenic mice expressing the four-repeat domain of human Tau ( $\mathrm{Tau}^{\mathrm{RD}}$, residues 244-372) were generated as described previously [8]. The pro-aggregant form $\mathrm{Tau}^{\mathrm{RD} \Delta}$ carried the mutation $\Delta \mathrm{K} 280$, the antiaggregant form $\mathrm{Tau}^{\mathrm{RD} \Delta \mathrm{PP}}$ carried the mutations $\Delta \mathrm{K} 280$ / I277P/I308P where the additional prolines prevent aggregation through $\beta$-structure (for details see [7]). Transgene expression was monitored and quantified by bioluminescence of luciferin via the co-expressed luciferase (for details see $[9,24]$. The Tau knockout mouse was created by $\mathrm{H}$. Dawson and colleagues by homologous recombination replacing exon 1 with a neomycin expression cassette [25]. Non-transgenic littermates of pro- and anti-aggregant mutants were used as controls. Transgenic animals were fed with doxycycline-containing pellets for 3 weeks to shut off mutant Tau gene expression in the first postnatal phase to prevent developmental disturbances. All animals were housed and tested according to standards of the German Animal Welfare Act.

\section{Hippocampal organotypic slice cultures}

Hippocampal organotypic slice cultures were prepared following [26] with modifications [27]. Briefly, 8 days old mice were decapitated, brains were rapidly removed, and hippocampi dissected at $4^{\circ} \mathrm{C}$. A McIIwain tissue chopper (Gabler, Bad Schwabach, Germany) was used to prepare $400 \mu \mathrm{m}$ thick transverse slices which were transferred to semi porous cell culture inserts (Millipore, Bedford, MA, USA; $0.4 \mathrm{~mm}$ ). Inserts containing 6 slices were placed in 6-well culture trays containing $1 \mathrm{~mL}$ of culture media (50\% Minimum Essential Medium (MEM), 25\% Hank's Balanced Salt Solution (HBSS), penicillin/streptomycin [all from PAA, Pasching, Austria], 25\% horse serum, $4.5 \mathrm{mg} / \mathrm{mL}$ glucose [Sigma-Aldrich, St. Louis, MO, USA], $\mathrm{pH}$ 7.4). The culture medium was changed on the first day after preparation and afterward every third day.

\section{Primary hippocampal cell culture}

Primary hippocampal neurons were isolated from embryonic E18 Sprague Dawley rats and plated on polyD-lysine-coated glass coverslips $(50 \mathrm{~g} / \mathrm{ml})$ at a density of 50,000 cells per well in 24 well plates (Corning or Sarstedt) as described previously [28]. Neurons were transfected with Lipofectamin (Invitrogen) at DIV 14-23. Per coverslip $0.6 \mu \mathrm{g}$ of plasmid DNA was used either with pAAV (plasmid Adeno Associated Virus)/pro-aggregant $\mathrm{Tau}^{\mathrm{RD} \Delta} /$ IRES (Internal Ribosomal Entry Site)/hrGFP (human recombinant green fluorescent protein) or pAAV/ IRES/hrGFP as a negative control plasmid. Transfections were carried out over a period of $72 \mathrm{~h}$.

\section{Inducible N2a cell-line}

Tau expressing N2a cell-lines were generated previously [29]. The stable N2a cell-lines N2a/Tet-ON/pro-aggregant $\mathrm{Tau}^{\mathrm{RD} \Delta}$ and $\mathrm{N2a}$ /Tet-ON/anti-aggregant $\mathrm{Tau}^{\mathrm{RD}} \Delta \mathrm{PP}$ were seeded on coverslips and grown confluently in Eagle's minimum essential medium supplemented with $10 \%$ fetal calf serum, $2 \mathrm{mM}$ glutamine, and $0.1 \%$ nonessential amino acids. The expression of constructs was induced by doxycycline and expression was continued for 4 days. On the fourth day expression was checked by bioluminescence. D-luciferin (Caliper Life Science) was added to the medium and bioluminescence was measured using an Ivis Spectrum imaging system (Caliper Life Science). 


\section{Electron microscopy}

For electron microscopic analysis of mossy fiber boutons, 4 adult wild-type animals and 4 pro-aggregant $\mathrm{Tau}^{\mathrm{RD} \Delta}$ transgenic mice were used. The animals were deeply anesthetized with a lethal dose of sodium pentobarbital and then transcardially perfused, first with $5 \mathrm{ml}$ of physiological saline, followed by approximately $150 \mathrm{ml}$ fixative solution (1\% glutaraldehyde and $4 \%$ paraformaldehyde in $0.1 \mathrm{M}$ phosphate buffer, $\mathrm{pH}$ 7.4). The fixative solution was perfused for approximately $15 \mathrm{~min}$. Then, the brains were removed from the skulls and post-fixed in fixative solution over night at $4^{\circ} \mathrm{C}$. After rinsing in $0.1 \mathrm{M}$ phosphate buffer $(\mathrm{pH} 7.4)$, the brains were sectioned on a vibratome (Leica VT1000S) in the coronal plane at a thickness of $200 \mu \mathrm{m}$. Sections containing the dorsal (septal) hippocampus were processed for electron microscopy by placing the tissue in $1 \%$ $\mathrm{OsO}_{4}$ for $30 \mathrm{~min}$. After careful washing (5 times, $5 \mathrm{~min}$ each) in distilled water, the sections were dehydrated in increasing concentrations of ethanol (block-staining the sections in $0.5 \%$ uranyl acetate in $70 \%$ ethanol for 1 hour). Thereafter, the sections were soaked in propylene oxide and finally embedded in Durcupan ACM resin (Fluca) and hardened at $56^{\circ} \mathrm{C}$ for at least 24 hours. The CA3 region was cut out and remounted on blank Durcupan blocks for thin sectioning. Thin sections were cut using an Ultracut (Leica) and a diamond knife. Sections were mounted on copper grids and post-stained with lead citrate. Electron micrographs of the stratum lucidum were taken at a magnification of $\times 5000$. Ten mossy fiber boutons from each animal were used for quantitative analysis. Bouton area, number of vesicles, and the length of synaptic contact zones were measured using SIS software (Münster, Germany). Student's t-test was used for statistical analysis.

\section{Histology}

Gallyas silver staining and immunohistochemistry - using antibodies: 12E8 (pSer262/pSer356, 1:2000, gift of Dr. P. Seubert, Elan, S. San Francisco), PHF1 (pSer396/pSer404, 1:50, gift of Dr. P. Davies, Albert-Einstein College, N.Y.), MC1 (conformational changes of tau, 1:10, Dr. P. Davies) were performed on $5 \mu \mathrm{m}$ paraffin sections according to published procedures $[3,8]$.

\section{$\mathrm{Ca}^{++}$imaging of mossy fiber boutons}

To load hippocampal slice cultures with Oregon Green 488 BAPTA 1-AM (OGB-1 AM), we added $4 \mu \mathrm{l} 20 \%$ Pluronic F-127 in DMSO (Invitrogen) and $36 \mu \mathrm{DMSO}$ to a $50 \mu \mathrm{g}$ vial of OGB-1 AM (Molecular Probes). The solution was added to slice culture medium to a final concentration of $10 \mu \mathrm{M}$. Slice cultures were submerged and incubated for $60 \mathrm{~min}$ at $37^{\circ} \mathrm{C}$. Slices were washed with slice culture medium and then transferred to HEPES- buffered saline (HBS; $130 \mathrm{mM} \mathrm{NaCl}, 5.4 \mathrm{mM} \mathrm{KCl} ; 10 \mathrm{mM}$ HEPES, $25 \mathrm{mM}$ glucose, $1.8 \mathrm{mM} \mathrm{CaCl} 2,1 \mathrm{mM} \mathrm{MgCl} 2$; ph 7.4) and allowed to recover for 30 min prior to an experiment. Imaging was performed with a Zeiss LSM 700 laser-scanning confocal microscope equipped with a 20x1A objective (Zeiss, Jena, Germany). Light from an argon laser $(488 \mathrm{~nm})$ was used for excitation and a FITC/ GFP filter set for emission. $\mathrm{Ca}^{++}$transients at individual mossy fiber boutons were evoked by applying $572 \mathrm{mM}$ potassium chloride $(\mathrm{KCl})$. The relative $\mathrm{Ca}^{++}$increment is calculated as $\Delta \mathrm{F} / \mathrm{F} 0$, where $\mathrm{F} 0$ is resting fluorescence intensity of OGB-1 after subtraction of background fluorescence, and $\Delta \mathrm{F}$ is the fluorescence increment from $\mathrm{F} 0$.

\section{Calcium imaging in cell-culture}

Prior to calcium imaging experiments N2a cell cultures were induced with doxycycline $(1 \mu \mathrm{g})$ for 4 days. N2a cell-lines and primary hippocampal neurons were washed at least 3 times with HEPES buffered saline. Thereafter cells were loaded with $10 \mu \mathrm{M}$ Fura 2-AM (Molecular Probes) for 30 minutes at $37^{\circ} \mathrm{C}$ and $5 \% \mathrm{CO}_{2}$ in HEPES-buffered saline. The Fura2-AM solution was removed and cells were washed three or more times and left for a few minutes in the incubator to allow complete de-esterification of the Fura dye. After washing, cultures were transferred to a submerged imaging chamber of an Examiner A1 microscope (Zeiss, Jena, Germany). Fura-2 fluorescence was imaged at room temperature (RT) in HEPES-buffered saline, using a $40 \times$ water immersion objective (Zeiss). The emission of Fura-2-loaded cells was collected at $510 \mathrm{~nm}$ after excitation at 340 and $380 \mathrm{~nm}$ respectively with a Sutter DCIV shutter (Sutter Instrument $\mathrm{Co}$, Navato, CA, USA). Images were taken at a rate of $1 \mathrm{~Hz}$. For baseline, intracellular $\mathrm{Ca}^{++}$levels were recorded for at least 30 seconds subsequently cells were stimulated with a high potassium solution $(286 \mathrm{mM} \mathrm{KCl})$ by manual application and recorded for another 90 seconds. In primary hippocampal cultures, neurons and astrocytes were distinguished on the basis of their morphology and delayed intracellular $\mathrm{Ca}^{++}$peak $(\sim 30 \mathrm{sec}$ after high $\mathrm{KCl}$ for neurons and $\sim 90 \mathrm{sec}$ for astrocytes).

\section{Electrophysiology}

To obtain preserved mossy fiber tracts, acute, transverse hippocampal slices were prepared from $13( \pm 1)$ month-old female mice as described before [30]. ACSF was adjusted by increased $\mathrm{Ca}^{++}$concentrations $(126 \mathrm{mM} \mathrm{NaCl}, 26 \mathrm{mM}$ $\mathrm{NaHCO}_{3}, 3 \mathrm{mM} \mathrm{KCl}, 2.5 \mathrm{mM} \mathrm{CaCl}, 1.3 \mathrm{mM} \mathrm{MgSO}$, $1.25 \mathrm{mM} \mathrm{NaH}_{2} \mathrm{PO}_{4}$ and $10 \mathrm{mM}$ glucose, saturated with $\left.95 \% \mathrm{O}_{2} / 5 \% \mathrm{CO}_{2}\right)$. After $1.5 \mathrm{~h}$ recovery period in a homemade interface chamber, slices were transferred to a submerged recording chamber at $30^{\circ} \mathrm{C}$. The mossy fiber tract was visualized by infrared (IR)/differential interference contrast (DIC) microscopy. As stimulation electrode, 
a patch-clamp pipette was used (1-2 M $\Omega$ ) to stimulate mossy fibers (mf) in the region of the hilus. Recording electrodes (2.5-3 M $\Omega$ ) were filled with ACSF and separated constantly $200 \mu \mathrm{m}$ from stimulation electrode. fEPSPs were $10 \times$ preamplified (custom made preamplifier) filtered at $1 \mathrm{kHz}$ and sampled at $10 \mathrm{kHz}$ using a HEKA double patch-clamp EPC 10 USB amplifier (HEKA Elektronik Dr. Schulze GmbH).

\section{Stimulation protocols and recording procedures}

Constant current pulses were elicited every $20 \mathrm{~s}(0.05 \mathrm{~Hz})$ with a pulse width of $0.1 \mathrm{~ms}$. Input output (I/O) curves were generated using stimulus intensities ranging from $10-100 \mu \mathrm{A}$ with an increment of $10 \mu \mathrm{A}$. In the same slice paired pulse facilitation (PPF) was evoked by a $50 \mathrm{~ms}$ inter-stimulus interval (ISI). In a next step frequency facilitation (ff) of the mossy fiber pathway was measured by switching stimulation frequency from $0.1 \mathrm{~Hz}$ to $1 \mathrm{~Hz}$. Only slices which showed robust ff and PPF of approximately 1.5 were used further on for mf-LTD recordings. LTD was induced by $1 \mathrm{~Hz}$ stimulation for $15 \mathrm{~min}$ (900 pulses) at $50 \%$ of the maximum stimulus intensity as revealed initially during the $\mathrm{I} / \mathrm{O}$ recording. At the end of each recording $5 \mu \mathrm{M}$ of the mGluRII receptor antagonist DCGIV (Tocris Biosciences) diluted in ACSF was washed in for at least $5 \mathrm{~min}$ to test for mossy fiber specificity. In case the fEPSP slope and amplitude were not reduced to more than $50 \%$ of the initial value, slices were excluded from further mossy fiber analysis.

\section{Immunofluorescence}

Brains from adult 13 month-old mice were fixed for $48 \mathrm{~h}$ in $4 \%$ PFA at $4{ }^{\circ} \mathrm{C}$ and horizontal, hippocampal freefloating sections with a thickness of $80 \mu \mathrm{m}$ were prepared with a vibratome (Leica VT 1200S, Wetzlar, Germany). Sections were rinsed with $0.4 \%$ TritonX in $5 \%$ horse serum for $1 \mathrm{~h}$ at RT. After washing with PBS first antibodies (PHF1 (pSer396/pSer404, Dr. P. Davies): 1:250; MC1 (Dr. P. Davies): 1:20) were incubated at $4^{\circ} \mathrm{C}$ over night. Secondary antibodies (donkey anti-mouse Alexa 488, Dianova) were incubated for 1:100 for $2 \mathrm{~h}$ at RT.

\section{Immunohistochemistry of slice cultures}

Slice cultures were left attached on the Millicell membrane and stained as free-floating sections in 6-well plates. Cultures were first fixed with $4 \%$ paraformaldehyde (PFA) in phosphate buffered saline (PBS) (PAA, Austria) for $2 \mathrm{~h}$ at $4^{\circ} \mathrm{C}$. After washing with PBS, slices were permeabilized by $0.1 \%$ TritonX-100/PBS for $90 \mathrm{~min}$ at RT. Slices were then blocked with $5 \%$ bovine serum albumin (BSA) for $2 \mathrm{~h}$ and afterwards incubated with primary antibody diluted in PBS for 3 days at $4^{\circ} \mathrm{C}$. After washing three times with PBS, slices were incubated with secondary antibody for 2 days at $4^{\circ} \mathrm{C}$. Finally, slices were incubated with the nuclear counterstain and dead cell indicator TO-PRO3 (Molecular Probes, US) for $15 \mathrm{~min}$ and washed three time with PBS before getting mounted with Permafluor mounting solution (Beckman Coulter, Paris, France. The following primary antibodies were used: pan-Tau antibody K9JA (Dako, Hamburg, Germany, Nr. A0024 (1:1000)), 12E8 (1:1000) for phosphorylated S262/S356 Tau (gift from Dr. P. Seubert, Elan Pharma, South San Francisco, CA, US) and Synaptophysin (1:1000; Sigma). All fluorescent (goat anti-rabbit/mouse cyanine 2 and 3)-labeled secondary antibodies were from Dianova (Hamburg, Germany) (1:1000).

\section{Dil labeling of organotypic slice cultures}

Hippocampal slice cultures were fixed at day 10 in vitro (DIV 10) in 4\% PFA for 2 hours, still attached to the semi-porous cell culture inserts. A DiI crystal was placed on the dentate gyrus followed by an incubation of 10 days at room temperature in 4\% PFA to allow diffusion. Mossy fiber boutons and dendritic spines were imaged by confocal microscopy using tetramethyl rhodamine isothiocyanate (TRITC)-filter settings. Image J (NIH, USA) was used to measure morphological parameters such as spine density, mf bouton diameter and filopodia from resulting Z-stacks. For 3D surface determination, boutons were reconstructed by Imaris software (Version 7.6.4; Bitplane, Switzerland). For structural analysis at least 10 slices were prepared from 5 different animals per group.

\section{Drug application}

Slice cultures were treated with compound bb14, a rhodanine-based Tau aggregation inhibitor identified in previous screens $[31,32]$. Compound bb14 was dissolved in $100 \%$ DMSO and added to the culture media at a final concentration of $15 \mu \mathrm{M}(0.15 \%(\mathrm{v} / \mathrm{v}) \mathrm{DMSO})$. Control slices were treated with the same amount of DMSO alone. In all experiments treatment was done for the entire cultivation period starting at DIV 1. During treatment, the compound was replenished once a day after preparation and later on every 3rd day.

\section{Statistics}

Throughout the study error bars denote standard error of the mean (SEM) except for ultrastructural analysis where errors denote standard deviation. Statistical hypothesis testing was done by using Prism5 (GraphPad, La Jolla, CA, USA), Statistica (Statsoft, Europe GmbH, Hamburg) and OriginPro8.5 (OriginLab cooperation, Northhampton, MA, USA). Evaluation of data was performed either by Student's t-test or One way ANOVA followed by Tukey's post-hoc test for morphological measurements in organotypic slices and multiple way repeated measure ANOVA was used for comparisons in electrophysiological recordings. Moreover, when groups did not have normal 
distribution the paired sample Wilcoxon signed rank test was used as a nonparametric test. p-values are indicated as follows: * $\mathrm{p}<0.05, * \mathrm{p}<0.01$, and ${ }^{* * *} \mathrm{p}<$ 0.001. Additional file 1: Supplemental experimental procedures.

\section{Results \\ Endogenous Tau becomes phosphorylated and aggregated in area CA3 of the hippocampus due to expression of the human Tau repeat domain $\Delta \mathrm{K} 280$}

The "mossy fiber pathway" denotes axonal projections from dentate gyrus (DG) granule cells to area CA3 of the hippocampus, where "giant" boutons innervate thorny excrescences at CA3 pyramidal cell dendrites and interneurons (feed forward inhibition). These projections lying within the hippocampal layer stratum lucidum (s.l., Figure 1a) are specifically prone to pathological Tau hyperphosphorylation and aggregation in a FTDP-17 based mouse model overexpressing the repeat domain of Tau with the mutation $\Delta \mathrm{K} 280\left(\mathrm{Tau}^{\mathrm{RD} \Delta}\right)$ in the forebrain $[7,8]$.

Since Tau is known to be hyperphosphorylated in several tauopathies $[33,34]$ we looked for Tau's phospho-status by using different phosphorylation-dependent antibodies (for a complete list of antibodies see Additional file 2: Table S1). Using the phospho-dependent antibody 12E8 (pSer262/ pSer356) we detected abnormally phosphorylated and mislocalized Tau in area CA3 a-c and DG in sagittal hippocampal sections from $13 \pm 1$ month-old mice (Figure 1b1). 12E8 immunoreactivity was detected in cell somata in the stratum pyramidale (s.p., Figure $1 \mathrm{~b} 1$ and b3) but not in control littermate slices (Figure 1b2). We also used the phospho-dependent antibody PHF1 (pSer396/pSer404), a marker of pathological phosphorylation of endogenous Tau. PHF1 showed exclusively axonal immunoreactivity of mossy fibers in the stratum lucidum (Figure 1c1, Additional file 3: Figure S1b and e) but not in control littermates (Figure 1c2, Additional file 3: Figure S1a). Indeed detailed inspection of PHF1 immunoreactivity in area CA3 demonstrated that apical dendrites of pyramidal cells were not PHF1 positive (Figure 1c3, white arrows). We confirmed the presence of pathologically, phosphorylated endogenous Tau in the mossy fiber tract with the antibodies PHF1 and AT-8 (pSer202/Thr205; Additional file 3: Figure S1a-d) by immunofluorescence. Moreover we used immunofluorescence to trace single mossy fiber axons with PHF-1 immunoreactivity projecting from granule cells towards CA3 pyramidal cells (Additional file 3: Figure S1e). Finally, human Tau expression was confirmed by western blotting from CA3 hippocampal homogenates in pro-and anti-aggregant mice (Additional file 4: Figure S2a). The phosphorylation sites AT180 and AT8 were detected by western blotting in pro- and anti-aggregant mice but not in control littermates and Tau knockout mice (Additional file 4: Figure S2b-c) and we found weak immunoreactivity against the $\mathrm{MC1}$ epitope demonstrating conformational change of Tau in that region (Additional file 4: Figure S2d).

Finally, Gallyas silver staining was applied to monitor Tau aggregation in our model (Figure 1d1). Similar to 12E8 immunoreactivity, Tau pathology occurred predominantly in somata of CA3 a-c pyramidal neurons of stratum pyramidale (Figure $1 \mathrm{~d} 1$ and $1 \mathrm{~d} 3$, white arrows), whereas there was no aggregation in control littermates (Figure 1d2).

\section{Tau is missorted to dendrites and somata in area CA3 of pro-aggregant $\operatorname{Tau}^{\mathrm{RD} \Delta}$ mice}

The above observations prompted us to investigate the mossy fiber pathway in more detail. We stained horizontal hippocampal slices with the pan-Tau antibody K9JA. In 13 month-old control littermate mice, Tau was restricted to axons in mossy fiber bundles in s.l. and there was neither dendritic nor somatic Tau immunoreactivity throughout CA3 a-c (Additional file 5: Figure S3a). By contrast, in pro-aggregant $\mathrm{Tau}{ }^{\mathrm{RD} \Delta}$ mice we observed missorting of Tau (endogenous and transgenic) into somatodendritic compartments (Additional file 5: Figure S3b). Under these circumstances Tau was detectable in all three hippocampal layers (s.r., s.l. and s.p., Additional file 5: Figure S3b, arrows). To better visualize mossy fibers and their projection targets (thorny excrescences) we used the lipophilic tracer DiI in combination with pan-Tau immunohistochemistry. This method highlighted Tau in mossy fiber boutons and postsynaptic, dendritic compartments in area CA3 a-c of pro-aggregant mice (Additional file 5: Figure S3f-h) whereas in control littermates pan-Tau immunoreactivity was consistently restricted to axonal and presynaptic "giant" bouton structures (Additional file 5: Figure S3c-e).

\section{Presynaptic pro-aggregant $\mathrm{Tau}^{\mathrm{RD} \Delta}$ impairs basal synaptic transmission, mossy fiber plasticity and reduces synaptic markers}

To test the patho-physiological consequences of presynaptic pro-aggregant $\mathrm{Tau}{ }^{\mathrm{RD}} \Delta$, we used field potential recordings in s.l. of area CA3. We stimulated mossy fibers in the hilus region $\mathrm{CA} 3 \mathrm{c}$, Figure 1a) and recorded mossy fiber field excitatory postsynaptic potentials (mf-fEPSP) in stratum lucidum of area CA3 b from $13 \pm 1$ month-old animals from pro-aggregant $\mathrm{Tau}^{\mathrm{RD} \Delta}$ and control littermates. We further included anti-aggregant $\mathrm{Tau}^{\mathrm{RD} \Delta \mathrm{PP}}$ [8] and Tau knockout (TKO) mice [25] in our study. Control littermates reached a maximum slope of $\mathrm{mf}$-fEPSP on average at $312.9 \mathrm{mV} / \mathrm{s}$ (nonlinear curve fit (Hill); $\mathrm{n}=4$; Figure 2a), well comparable to the anti-aggregant mice average maximum slope $(317.25 \mathrm{mV} / \mathrm{s}$; nonlinear curve fit (Hill); $n=5$; Figure 2a). In contrast pro-aggregant mice reached only a maximum mf-fEPSP slope of 


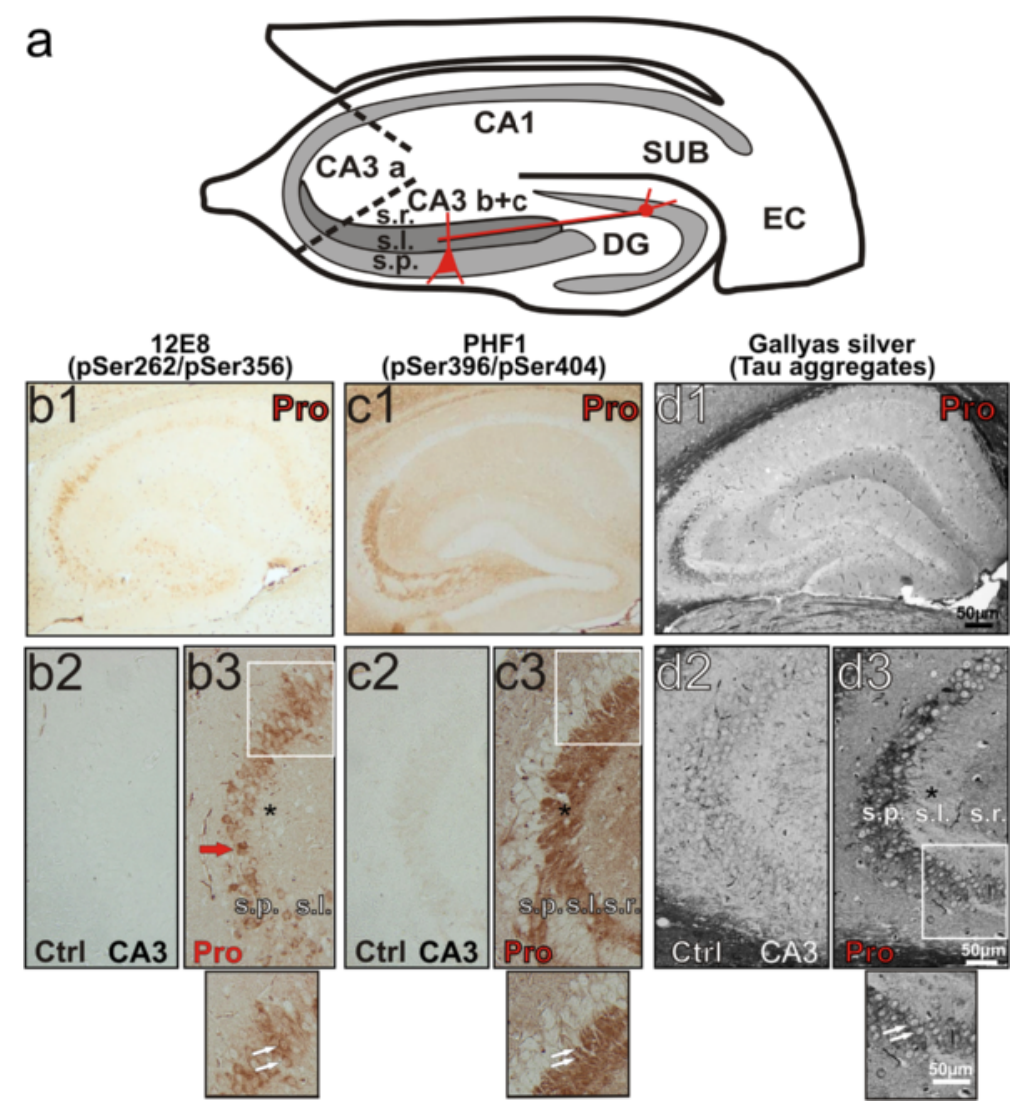

Figure 1 Tau pathology in stratum pyramidale and stratum lucidum of area CA3 in sagittal sections from $13 \pm 1$ month old pro-aggregant Tau ${ }^{\mathrm{RD} \Delta}$ mice. (a) Schematic drawing of a hippocampal mouse section containing the entorhinal cortex (EC). The drawing depicts the main hippocampal output region, the subiculum (SUB) followed by the cornu ammonis (CA) regions with areas CA1, CA3a, CA3b, and CA3C (hilus). The main input region from the EC to the hippocampus is the dentate gyrus (DG) containing the granule cells (red) which project to proximal apical dendrites of area CA3 principal cells (red). s.r. = stratum radiatum; s.l. = stratum lucidum; s.p. = stratum pyramidale. (b1-b3) Somatodendritic mislocalization of phosphorylated Tau (12E8 immunoreactivity) in pyramidal neurons (B3 red arrow) and 12E8-immunoreactivity of stratum lucidum (s.l.,b3, asterisk) of the CA3 region in $13 \pm 1$ month-old pro-aggregant mice (Pro). In contrast there is no 12 E8 immunoreactivity in area CA3 of control littermates (Ctrl, b2). Magnification square from region (b3, white square) depicts $12 \mathrm{E} 8$ immunoreactivity in somata of pyramidal neurons (white arrows). (c1-c3) PHF1-Tau antibody detects Tau phosphorylation exclusively in stratum lucidum of pro-aggregant mice (Pro, c1). CA3 pyramidal cell bodies and their dendrites are spared (c3, white arrows). Control littermates show no PHF1 immunoreactivity (c2). A zoom-in of a region in C3 (white square) demonstrates that PHF-1immunoreactivity is found in s.l. with apical dendrites of CA3 pyramidal neurons are spared (white arrows). (d1-d3) Using Gallyas silver staining to monitor Tau aggregation we found aggregates predominantly in CA3a-c pyramidal neurons of s.p. (d1 $\mathbf{1}$ and d $\mathbf{d}$ ), whereas aggregation is absent in control littermates (d2). Representative images from at least three different mice per group showing consistent staining were selected.

177.34 $\mathrm{mV} / \mathrm{s}$ (nonlinear curve fit (Hill); $\mathrm{n}=5$; Figure $2 \mathrm{a}$ ). Notably TKO mice showed a maximum average $\mathrm{mf}-$ fEPSP of $161.2 \mathrm{mV} / \mathrm{s}$ (nonlinear curve fit (Hill); $\mathrm{n}=6$; Figure 2a). Pro-aggregant and remarkably TKO mice both revealed a pronounced decrease in the input/output (I/O) curve, compared with control littermates (multiple way repeated measure ANOVA: pro-aggregant vs. control littermates: group effect $\mathrm{p}=0.014$; TKO vs. control littermates: multiple way repeated measure ANOVA: group effect $\mathrm{p}=0.001$; Figure $2 \mathrm{a}$ ). However, at the age of 2 months, the pro-aggregant mice did not differ from control littermates in basal synaptic transmission of the mossy fiber pathway demonstrating the progressive nature of this phenotype. Two month-old control littermate mice and pro-aggregant mice both reached the maximum fEPSP slope at $90 \mu \mathrm{A}$ stimulation intensity $(165.2 \pm 22.4 \mathrm{mV} / \mathrm{s}, \mathrm{n}=6$ and $169.1 \pm 57.3 \mathrm{mV} / \mathrm{s}, \mathrm{n}=13$ respectively; Figure 2a).

Next we investigated short-term plasticity measured by paired pulse facilitation (PPF). Pro-aggregant mice revealed a significant reduction of $\mathrm{mf}-\mathrm{PPF}$ compared to control littermates (paired pulse ratio control: $1.46 \pm 0.1$, $\mathrm{n}=24$; paired pulse ratio pro-aggregant: $1.25 \pm 0.03, \mathrm{n}=34$; t-test: $\mathrm{p}=0.023$; Figure $2 \mathrm{~b}$ ), whereas anti-aggregant mice 
and Tau knockout mice differed not significantly from control littermates (anti-aggregant: $1.33 \pm 0.06, \mathrm{n}=22$, t-test: $\mathrm{p}=0.296$; TKO: $1.32 \pm 0.06, \mathrm{n}=33$, t-test: $\mathrm{p}=$ 0.222 ; Figure $2 \mathrm{~b}$ ). 2 month-old pro-aggregant mice however displayed no impairment of PPF compared to control littermates (paired pulse ratio control: $1.53 \pm 0.12$, $\mathrm{n}=19$ and paired pulse ratio pro-aggregant: $1.45 \pm 0.14$; $\mathrm{n}=15$; data not shown). Mossy fiber frequency facilitation (mf-ff) was decreased in pro-aggregant mice (last 20 stimulation pulses displayed in graphs: $167.4 \pm 4 \%$ of baseline, $\mathrm{n}=11$ compared to control littermates: 208.4 $\pm 6 \%$ of baseline, $n=6$; multiple way repeated measure
ANOVA: group effect $p=0.019$, Figure 2c). In antiaggregant mice, mossy fiber frequency facilitation was scarcely and not significantly reduced confirming previous results $(177.9 \pm 5 \%$ of baseline, $n=4$, Figure $2 d$; multiple way repeated measure ANOVA: group effect $\mathrm{p}=0.455$, [8]). TKO mice displayed frequency facilitation well comparable to control mice $(199.3 \pm 8 \%$ of baseline, $\mathrm{n}=5$, Figure 2e). Finally when comparing 2 month-old control littermates with pro-aggregant siblings we could not detect any differences in mf-ff (229.4 $\pm 7.7 \%$ of baseline, $n=10$ and $240 \pm 12.1 \%$ of baseline, $\mathrm{n}=7$; data not shown).

\section{a CA3 $\mathrm{mf}-\mathrm{i} / \mathrm{o}$ middle age b $\mathrm{CA} 3 \mathrm{mf}-\mathrm{ppf}$
middle age \\ C $\quad$ CA3 $\mathrm{mf}-\mathrm{ff}$ middle age}
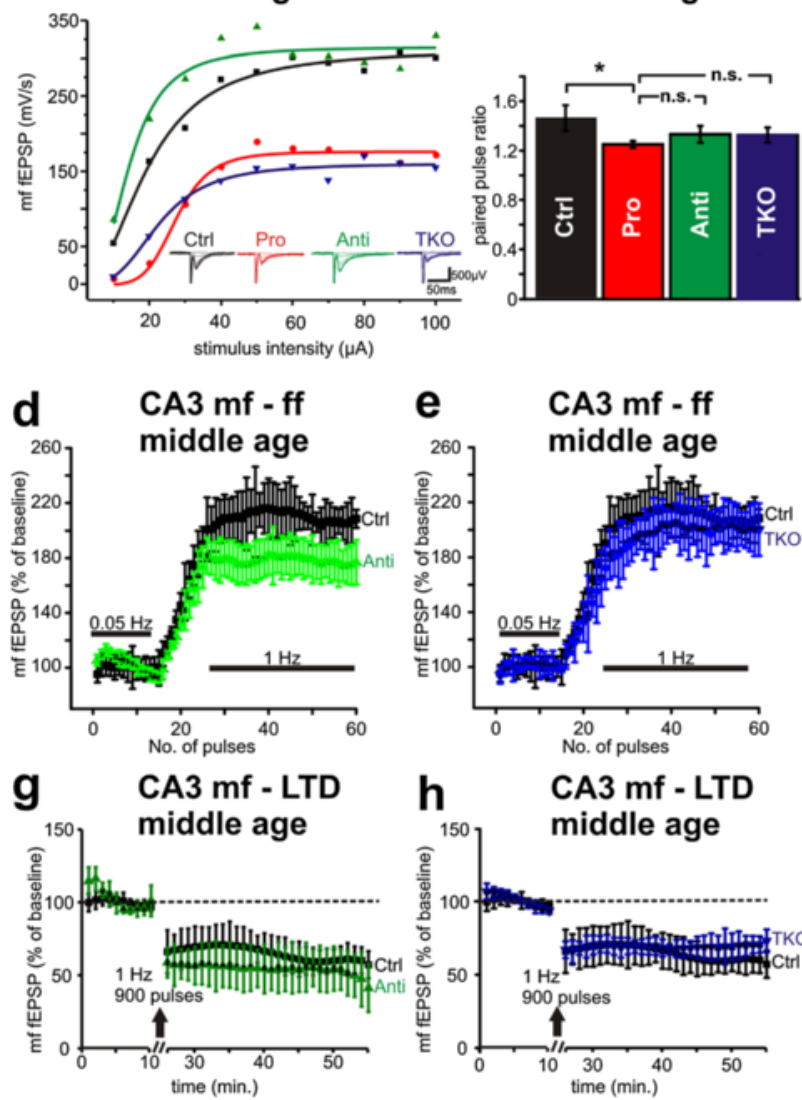
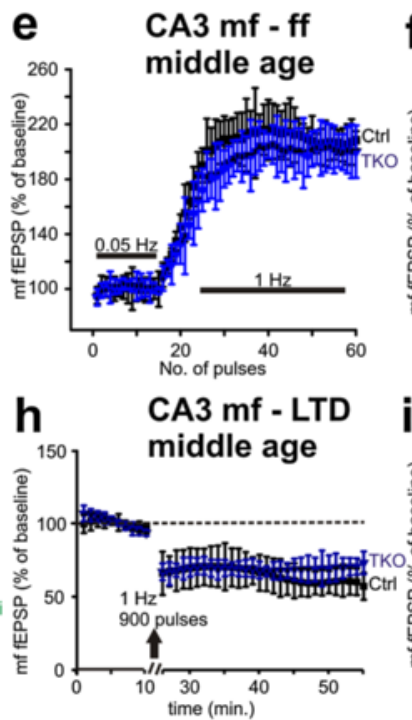

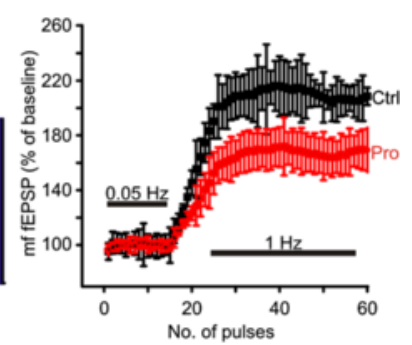

f CA3 mf - LTD middle age

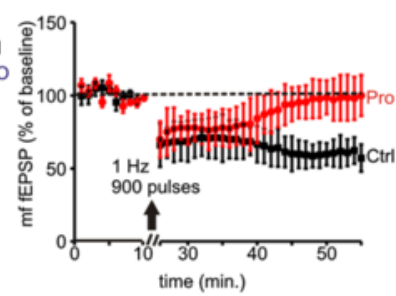

CA3 mf - LTD young mice

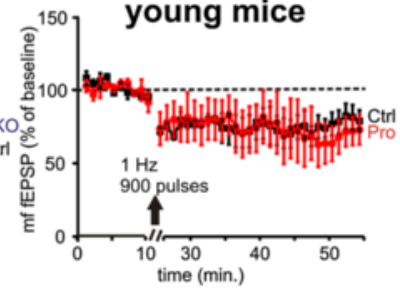

Figure 2 Functional impairment of the mossy fiber pathway after 13 months of Tau ${ }^{\text {RD } \Delta}$ expression. (a) Basal synaptic transmission of mossy fibers measured by input output curves (mf-i/o) is decreased in mossy fibers of pro-aggregant (Pro, red circles) and Tau knockout (TKO, blue triangles) mice compared to control littermates (Ctrl, black squares) and anti-aggregant (Anti; green triangles) animals. (b) Paired pulse facilitation of the mossy fiber pathway (mf-ppf) is significantly impaired in pro-aggregant mice (Pro, red column) compared to control littermates (Ctrl, white column), but not changed significantly if compared to anti-aggregant (Anti, green column) and Tau knockout (TKO, blue column) mice. (c) Frequency facilitation of the mossy fiber pathway (mf-ff) is reduced $\sim 40 \%$ in pro-aggregant animals (Pro; red circles) compared to wildtype littermate control mice (Ctrl, black squares). (d) Anti-aggregant mice (Anti, green triangles) are less dramatically affected in terms of mf-ff impairment ( 30\%) compared to control mice. (e) Tau depleted mice (TKO, blue triangles) show no differences in mf-ff compared to control animals (Ctrl, black squares). (f) Long-term depression (LTD) of mossy fiber field excitatory postsynaptic potential (mf-LTD) induced by low frequency stimulation is not expressed in pro-aggregant mice (Pro, red circles), whereas control littermates (Ctrl, black squares) show a synaptic depression of about - $30 \%$ of baseline. (g) Mossy fiber LTD in anti-aggregant mice (Anti, green triangles) is not different from control littermates. (h) Endogenous Tau is not necessary for normal mossy fiber LTD as shown by Tau knockout mice (TKO, blue triangles). (i) mf-LTD in 2 month old mice is expressed in pro-aggregant mice (Pro, red circles) and control littermates (Ctrl, black squares). Both groups show a synaptic depression of about $-30 \%$ of baseline. Error bars represent SEM. Values represent recordings from at least 5 animals per group. 
Mossy fiber long-term depression (mf-LTD) is expressed at the presynaptic site [22] and depends on proper neuronal $\mathrm{Ca}^{++}$dynamics [23]. In control littermate mice, LTD induction by low frequency stimulation (LFS) led to an average synaptic depression of $-31.1 \pm 0.5 \%(n=8$, Figure 2f) of the initial baseline mf-fEPSP slope, whereas in pro-aggregant mice LTD was induced in the first 15 minutes after LFS, but was no longer present during the last 10 minutes of recording (reduction only $-2.2 \pm 0.4 \%$; $=7$; Figure $2 \mathrm{f}$ ). Therefore mf-LTD was significantly impaired in pro-aggregant mice compared to control littermates (paired sample Wilcoxon signed rank test, $\mathrm{p}=0.0019$, last 10 minutes of recording). In contrast, the same LTD protocol evoked a LTD expression closely comparable to control mice in anti-aggregant and TKO mice (Figure $2 \mathrm{~g}$ and $2 \mathrm{~h}$ respectively). Moreover comparing young cohorts of proaggregant mice and non-transgenic siblings we found no differences in LTD expression (last 10 minutes of recording, control littermates: $-23.6 \pm 1.2 \%$ of baseline recording and pro-aggregant: $-31.8 \pm 1.3 \%$ of baseline, Figure $2 \mathrm{i}$ ). Consistently we found in CA3 homogenates dissected from pro-aggregant $\mathrm{Tau}^{\mathrm{RD} \Delta}$ mice a reduction of the presynaptic vesicle protein synapsin1 and synaptophysin (Additional file 3: Figure S2e and f). This was accompanied by a loss of the postsynaptic markers PSD95 and the NMDA receptor NR1 subunit (Additional file 3: Figure S2e and f).

\section{Pro-aggregant $\mathrm{Tau}^{\mathrm{RD} \Delta}$ leads to pathological Tau accumulation in presynapses and impairs synapse morphology}

Mossy fiber pre-synapses, the "giant" boutons, have unique morphological features: Their diameter ranges between $2-5 \mu \mathrm{m}$ and filopodia emanate from their surface [35-37]. We randomly labeled mossy fibers in acute, horizontal slices from $13 \pm 1$ month-old mice with the lipophilic dye DiI by using a biolistic gene-gun in order to identify mossy fiber "giant" boutons (Figure 3a). As morphological criteria for identification of "giant" boutons we defined proximity to thorny excrescences of CA3 pyramidal neurons, their size and at least 1 filopodium (Figure $3 \mathrm{~b}$ ). The diameter of such "giant" boutons (Figure $3 \mathrm{f}-\mathrm{j}$ ) showed a pronounced increase of $\sim 45 \%$ in pro-aggregant $\mathrm{Tau}^{\mathrm{RD} \Delta}$ mice compared with control littermates (pro-aggregant: $4.2 \pm 0.2 \mu \mathrm{m}, \mathrm{n}=25$ and control: $2.8 \pm 0.1 \mu \mathrm{m}, \mathrm{n}=25$, Two-sample t-test, $\mathrm{p}<0.001$; Figure $3 \mathrm{f}$ and g). In slices from anti-aggregant mice we did not find this pathological phenotype (bouton diameter: 2.99 \pm $0.1 \mu \mathrm{m}, \mathrm{n}=43$; Figure $3 \mathrm{~h}$ ), whereas TKO mice displayed a size increase closely comparable to pro-aggregant mice $(4.2 \pm 0.2 \mu \mathrm{m}, \mathrm{n}=33$; Figure 3i). Enlarged boutons in pro-aggregant mice contain conformational altered endogenous Tau (detected with MC1 antibody; Figure 3d and e), which was not observed in control littermates (Figure 3c).

Next, we made use of organotypic slice cultures, since this system is particularly advantageous for long distance granule cell-CA3 axonal connections [38,39]. With DiI labeling we detected granule cell-CA3 mossy fiber connections in DIV 10 slices (Figure 4a and b), a time point when we already detected phosphorylated and mislocalized Tau in $\mathrm{Tau}^{\mathrm{RD} \Delta}$ slices (Figure 5d1-6), well comparable with results from acute slices. It was possible to label boutons as well as thorny excrescences in area CA3 (Figure 4c). In pro-aggregant slices the dendritic spine density $(1.26 \pm 0.07$ spines $/ \mu \mathrm{m})$ was reduced by $\sim 20 \%$ compared to control littermate slices $(1.56 \pm 0.07$ spines $/ \mu \mathrm{m})$. This reduction was prevented by adding the Tau aggregation inhibitor bb14 [31] to pro-aggregant slices at DIV $0\left(1.49 \pm 0.05\right.$ spines $/ \mu \mathrm{m} ; \mathrm{F}_{(2 / 81)}=5.851 ; \mathrm{p}=$ 0.0042; Figure 4d,e).

In organotypic slices we detected pan-Tau immunoreactivity in mossy fiber boutons from control littermates (Figure $5 \mathrm{a} 1$ and $\mathrm{c} 1$ ) and $\mathrm{Tau}^{\mathrm{RD} \Delta}$ (Figure $5 \mathrm{~b} 1$ and $\mathrm{d} 1$ ) at DIV 5 and 10. We confirmed such Tau containing boutons by co-localization with presynaptic marker protein synaptophysin (Figure 5c7-c9 and d7-d9). In proaggregant $\mathrm{Tau}{ }^{\mathrm{RD} \Delta}$ slices we observed strong $12 \mathrm{E} 8 \mathrm{immu}-$ noreactivity in mf-boutons at DIV 10, which was not seen in control cultures either at DIV 5 or 10 (compare Figure 5d4-d6 with Figure 5a2 and c2). At DIV 5, 12E8 phosphorylation in $\mathrm{Tau}^{\mathrm{RD} \Delta}$ slices (Figure 5b1-b3) was weaker when compared to DIV 10 and in particular present in the postsynaptic compartment. In contrast, 12E8 immunoreactiviy was found in pre-and postsynaptic compartments at DIV 10 (Figure 5d4-d6).

The expression of pro-aggregant $\mathrm{Tau}^{\mathrm{RD} \Delta}$ led to a $42 \%$ increase in diameter of "giant" mf-boutons, comparable to hippocampal slices from adult mice, which was prevented when the aggregation inhibitor bb14 was added to the preparation (control: $3.20 \pm 0.13 \mu \mathrm{m}$; pro-aggregant: $4.54 \pm 0.16 \mu \mathrm{m}$; pro-aggregant + bb14: $3.86 \pm 0.20 \mu \mathrm{m}$; $\mathrm{F}_{(2 / 83)}=20.66 ; \mathrm{p}<0.0001$; Figure $5 \mathrm{e}$ and $\mathrm{f}$ ). In agreement with this, the 3D surface area of pro-aggregant boutons was larger $(\sim 74 \%)$ than in control littermate slices (control: $37.97 \pm 2.69 \mu \mathrm{m}^{2}$; pro-aggregant: 66.24 \pm $6.30 \mu^{2}$; pro-aggregant + bb14: $50.16 \pm 3.41 \mu \mathrm{m}^{2} ; \mathrm{F}_{(2 / 56)}=$ $10.67 ; \mathrm{p}<0.0001$; Figure $5 \mathrm{~g}$ ). We measured the average distance between mossy fiber boutons as a function of total excitation strength and observed an increased by $~ 51 \%$ in pro-aggregant $\mathrm{Tau}^{\mathrm{RD} \Delta}$ slices $(185.4 \pm 22.3 \mu \mathrm{m})$ compared to control littermates $(122.9 \pm 18.5 \mu \mathrm{m}$, Figure $5 \mathrm{~h})$. Again compound bb14 prevented this effect on mf-boutons (131.3 $\pm 6.7 \mu \mathrm{m}$, Figure $5 \mathrm{f})$.

As a measure of feedforward inhibitory drive we determined the length and number of filopodia per bouton. 


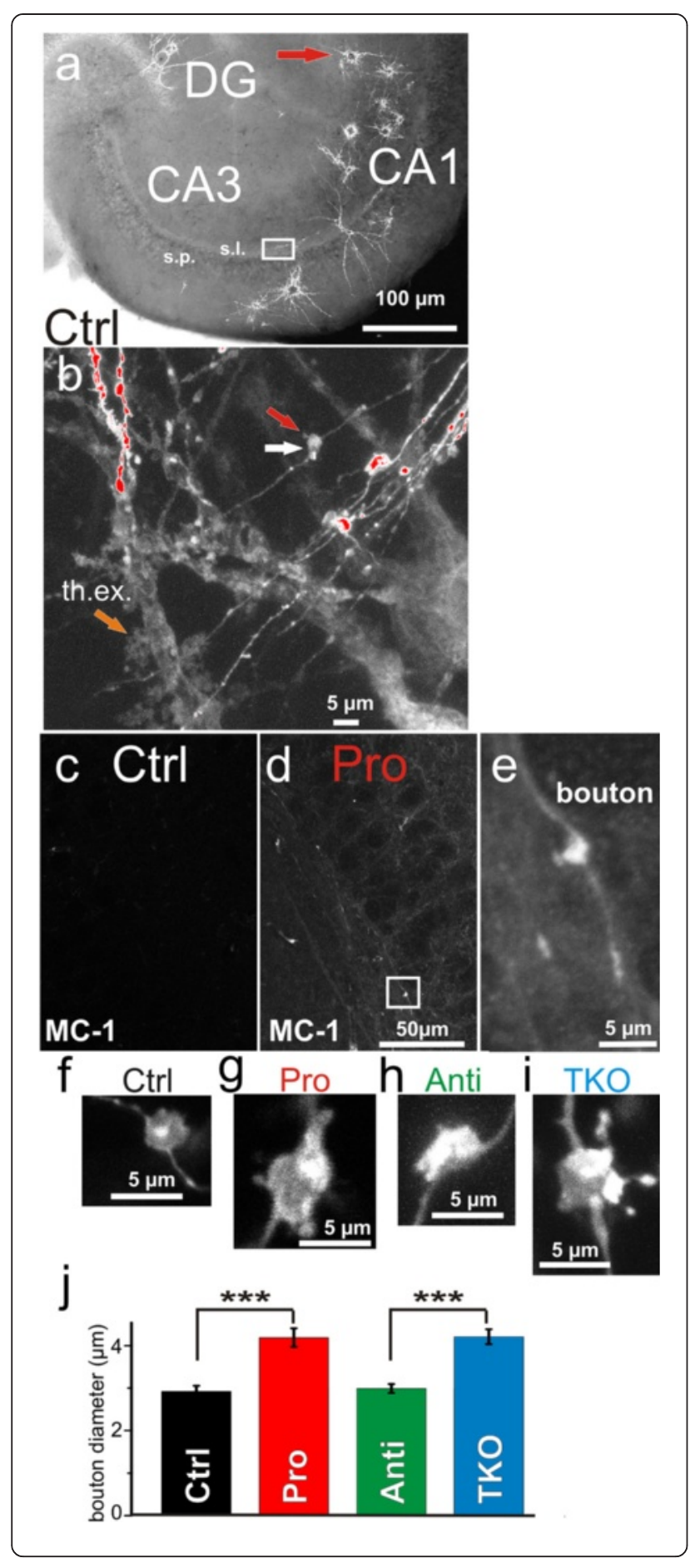

Figure 3 Mossy fiber presynapse morphology is altered because of $\mathrm{Tau}^{\mathrm{RD} \Delta}$ expression. (a) Microphotograph depicting an example of an acute, horizontal slice preparation shot with Dil coated gold particles (red arrow) to obtain neuronal membrane staining. Hippocampal sub-regions dentate gyrus (DG), CA3 and CA1 are visible. (b) Higher magnification of region of interest marked in (a) (white square) located in stratum lucidum of area CA3. Characteristic structural, postsynaptic features of CA3 pyramidal neurons are highlighted (thorny excrescences (th.ex.), orange arrow). Moreover, mossy fiber axons with boutons and filopodia are visible and correspond to the criteria for bouton selection (red arrow = filopodium; white arrow = bouton body). (c) Immunohistological detection of conformation altered Tau with MC-1 antibody in a control littermate mouse at $13 \pm$ 1 month, display no staining. (d) MC-1 immunofluorescence staining in aged matched pro-aggregant mouse (Pro) in s.l. Immunoreactivity is detected. (e) Higher magnification of the indicated region in ( $\mathbf{d}$; white square). MC-1 immunostaining revealed immunoreactivity in mossy fiber boutons. (f) Example of a mossy fiber "giant" bouton in control littermate mice (Ctrl). (g) Mossy fiber bouton of a pro-aggregant mouse (Pro) with filopodia emanating from the bouton surface. (h) Area CA3 mossy fiber bouton of an anti-aggregant mouse (Anti). (i) Example of a Tau knockout mouse bouton (TKO). (j) Measurement of bouton diameter in control littermate (black column), pro-aggregant (red column), anti-aggregant (green column) and Tau knockout mice (blue column) illustrating an increase of 45\% in diameter in pro-aggregant and Tau knockout mice. (10 slices prepared from at least 3 different animals per group). Error bars $=$ SEM; $p$-value $<0.001^{* * *}$

Filopodia were defined as described elsewhere [40] as emanating from the main body of the bouton, with lengths of $1-5 \mu \mathrm{m}$. The filopodia number increased somewhat $(\sim 21 \%$, control: $1.56 \pm 0.17$; pro-aggregant: $1.89 \pm 0.17$; pro-aggregant + bb14: $1.77 \pm 0.23 ; \quad \mathrm{F}_{(2 / 83)}=$ $0.9031 ; \mathrm{p}=0.4092$; Figure $5 \mathrm{i}$ ) and correspondingly filopodia lengths were reduced to a similar extent so that the total filopodia length remained roughly the same ( 17\%, control: $1.66 \pm 0.16 \mu \mathrm{m}$, pro-aggregant: $1.39 \pm$ $0.08 \mu \mathrm{m}$, pro-aggregant + bb14: $1.69 \pm 0.24 \mu \mathrm{m} ; \mathrm{F}_{(2 / 134)}=$ 1.656, $\mathrm{p}=0.2207$; Figure 5j).

\section{The synaptic vesicle density from pro-aggregant mice} was severely reduced in mossy fiber "giant" boutons Mossy fiber boutons in the stratum lucidum of CA3 were easily identified by their unique fine-structural characteristics. Thus, the thin unmyelinated preterminal mossy fiber axons gave rise to giant boutons that were densely filled with clear synaptic vesicles. Postsynaptic complex spines protruded deeply into the presynaptic boutons. At low magnification, no major differences in the fine structure of mossy fiber boutons were noticed between control littermate animals and pro-aggregant mice (13 \pm 1 month, 4 mice per group). In fact, an estimation of the lengths of synaptic contact zones (active zones; az, Figure $6 \mathrm{a}$ and b) did not reveal statistically significant differences between genotypes (control: $153.2 \pm$ $31.8 \mathrm{~nm}$; pro-aggregant mice $150.7 \pm 36.1 \mathrm{~nm} ; \mathrm{p}=0.80876$, Figure $6 \mathrm{c})$. However, we regularly noticed a reduction in 


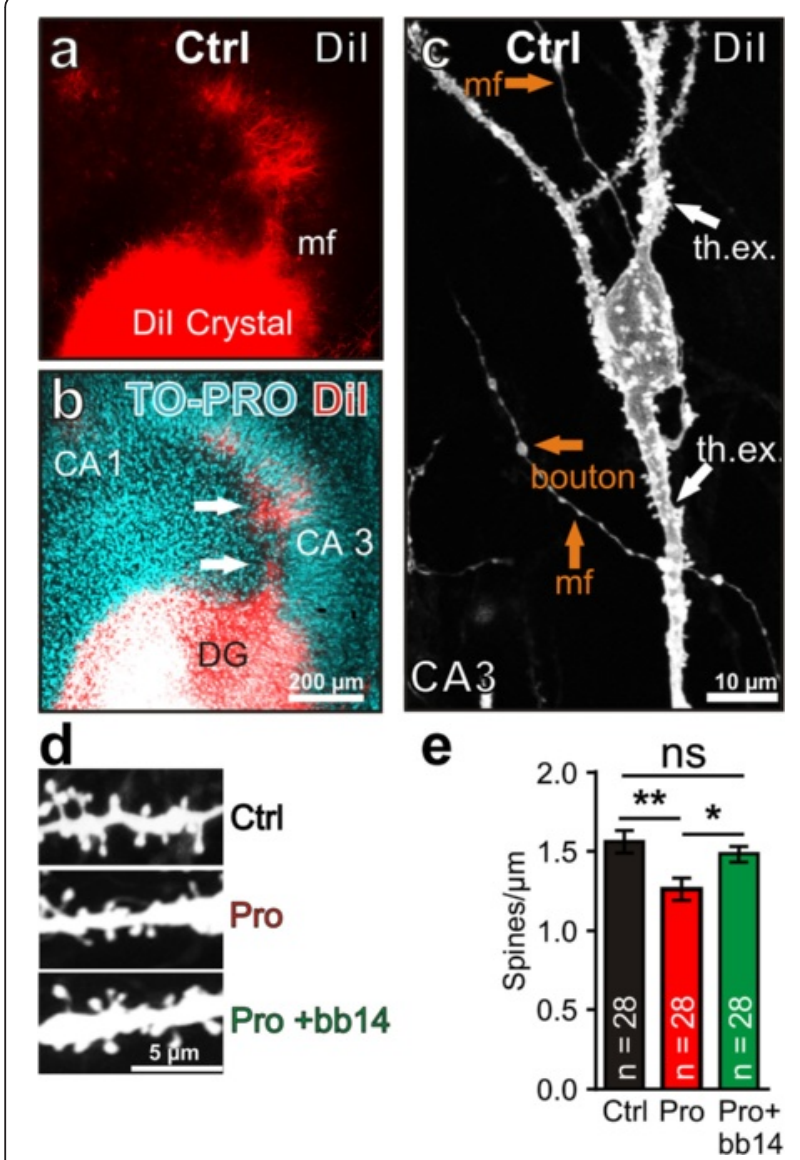

Figure $4 \mathrm{Tau}^{\mathrm{RD} \Delta}$ expression causes morphological changes of the DG - CA3 postsynapse in hippocampal organotypic slice cultures at DIV 10. (a) A Dil crystal was placed on the dentate gyrus of fixed hippocampal organotypic slices from pro-aggregant mice or control littermates. Dil labeled mossy fibers and CA3 pyramidal neurons were imaged 10 days later. (b) Nuclear counterstaining with TO-PRO was used to visualize hippocampal sub- regions. Arrows indicate Dil labeled mossy fibers. (c) Higher magnification of a single CA3 pyramidal neuron displays thorny excrescences (th.ex.) in the stratum lucidum and stratum oriens as well as projecting mossy fibers $(\mathrm{mf})$ from the dentate gyrus granule cells with large boutons. (d) Examples of thorny excrescences dendritic spines from CA3 pyramidal neurons taken from control (Ctrl), pro-aggregant (Pro) and pro-aggregant slices treated with Tau aggregation inhibitor bb14 (Pro + bb14). (e) Dendritic spine density of CA3 neurons was reduced by 20\% in pro-aggregant (Pro) vs. control littermate slice cultures (Ctrl) (10 slices prepared from 5 different animals per group). This effect is abolished when pro-aggregant slice cultures are treated with the aggregation inhibitor bb14 (Pro + bb14) (One way ANOVA followed by Tukey's post-hoc test ${ }^{*}$ p-value $<0.01$; ${ }^{*} p$-value $\left.<0.05\right)$. Error bars represent SEM.

the number of synaptic vesicles in the mossy fiber boutons of pro-aggregant animals. While vesicles were densely packed and almost completely filled the mossy fiber terminals of control littermates (Figure 6a), vesicle accumulations were rare in the boutons from transgenic mice, and there were frequent bouton areas containing only a few scattered vesicles (Figure 6b). Indeed, the number of synaptic vesicles $/ \mu \mathrm{m}^{2}$ bouton area was significantly decreased in $\mathrm{Tau}^{\mathrm{RD} \Delta}$ transgenic mice when compared to control littermates (control: $206.1 \pm 47.0$ vesicles $/ \mu \mathrm{m}^{2}$; transgenic mice $77.3 \pm 21.5$ vesicles $/ \mu \mathrm{m}^{2} ; \mathrm{p}=7.4487 \times$ $10^{-10}$, Figure $\left.6 \mathrm{~d}\right)$.

\section{$\mathrm{Ca}^{++}$influx is attenuated due to pro-aggregant $\mathrm{Tau}^{\mathrm{RD} \Delta}$} expression in mossy fiber boutons before tangle formation Normal $\mathrm{Ca}^{++}$signaling during resting and active neuronal states is essential for neuronal survival and synaptic plasticity [41]. In the present study we wanted to know if depolarization dependent $\mathrm{Ca}^{++}$dysregulation at the mossy fiber presynapse could be responsible for the described effects of pro-aggregant $\mathrm{Tau}^{\mathrm{RD} \Delta}$ on transmission and plasticity. Therefore we imaged $\mathrm{Ca}^{++}$influx in mossy fiber boutons in s.l. of area CA3 in slice cultures loaded with Oregon green bapta (OGB, Figure 7). After membrane depolarization, we observed an increase of intracellular $\mathrm{Ca}^{++}$concentration in axons with a peak in bouton-like structures compared with $\mathrm{Ca}^{++}$influx at the axonal shaft (data not shown), indicating that functional ion channels are enriched on the bouton membrane. At DIV 5 the $\mathrm{KCl}$-induced $\mathrm{Ca}^{++}$influx was comparable in boutons from pro-aggregant $\mathrm{Tau}^{\mathrm{RD} \Delta}$ slices and control littermates (pro-aggregant: $222.1 \pm 12.4 \%, \mathrm{n}=10$ and control: $249.7 \pm 32.8 \%$ of baseline, $n=9$; prepared from at least 5 animals per group, Figure $7 \mathrm{a}-\mathrm{b}$ and e). However at a later time point (DIV 10) there was a pronounced reduction by $106.4 \%$ in pro-aggregant Tau ${ }^{\mathrm{RD}} \Delta$ expressing slices, compared with controls (control: $302.3 \pm 21.1 \%$ of baseline, $\mathrm{n}=20$ and pro-aggregant: $195.9 \pm 18.2 \%$ of baseline, $n=17$; prepared from at least 5 animals per group) Figure $7 \mathrm{c}-\mathrm{d}$ and $\mathrm{f}$ ).

For comparison we looked at the immediate effect of pro-aggregant $\mathrm{Tau}^{\mathrm{RD} \Delta}$ expression on depolarization induced $\mathrm{Ca}^{++}$influx in rat primary hippocampal neuronal cell cultures. We transiently transfected neurons to express pro-aggregant $\mathrm{Tau}{ }^{\mathrm{RD} \Delta}$ plus GFP, compared with neurons expressing GFP only (Figure $8 \mathrm{a}-\mathrm{d}$ ). There was a pronounced reduction $(-60 \%)$ of $\mathrm{KCl}$-induced $\mathrm{Ca}^{++}$in $\mathrm{Tau}^{\mathrm{RD} \Delta}+$ GFP expressing neurons (GFP only: 263.4 \pm 18.6\%; $\mathrm{n}=7$ and pro-aggregant $\mathrm{Tau}^{\mathrm{RD} \Delta}+\mathrm{GFP}: 203.4 \pm$ $19.7 \% ; \mathrm{n}=7 ; \mathrm{p}=0.014$, paired T-test; Figure $8 \mathrm{e})$. This confirms that intracellular $\mathrm{Tau}^{\mathrm{RD}} \Delta$ impairs the influx of $\mathrm{Ca}^{++}$after membrane depolarization, both in slices and in primary neurons.

\section{The reduction of $\mathrm{Ca}^{++}$influx after membrane} depolarization is exacerbated with increasing aggregation of pro-aggregant $\mathrm{Tau}^{\mathrm{RD} \Delta}$ in N2a cells

To test if aggregation directly contributes to the observed reduction in $\mathrm{Ca}^{++}$influx after activity induction we made use of an inducible Tet-ON N2a cell line expressing pro-aggregant $\mathrm{Tau}^{\mathrm{RD} \Delta}$ and the reporter gene 


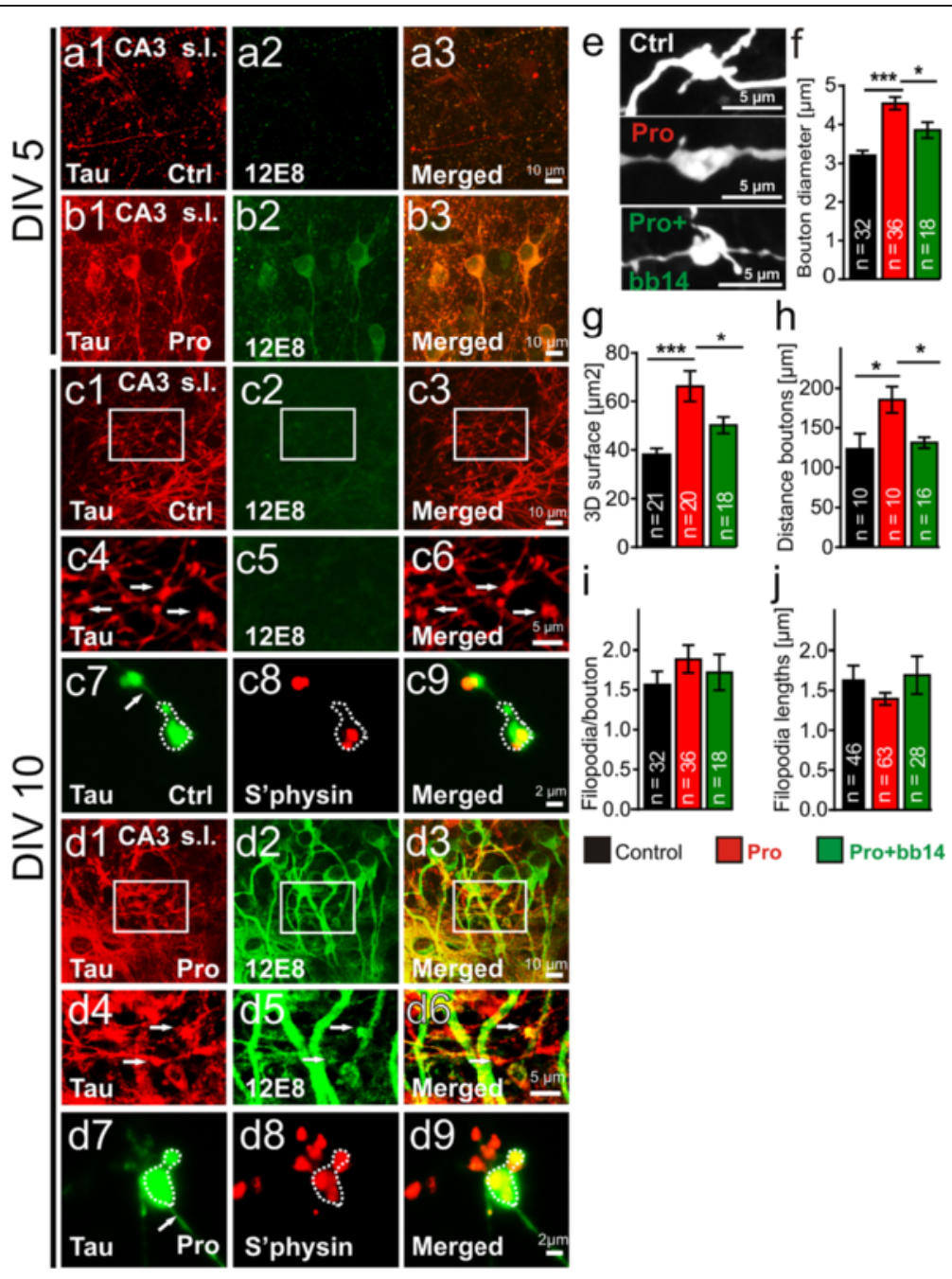

Figure 5 Expression of $\mathrm{Tau}^{\mathrm{RD} \Delta}$ causes morphological changes of mossy fiber boutons in hippocampal slice cultures. Photomicrographs of slice cultures from control (Ctrl) or pro-aggregant-mice (Pro) at DIV5 (a1-b3) and DIV10 (c1-d9); area CA3-immunostaining against pan-Tau $(\mathrm{K} 9 \mathrm{JA}, \mathrm{a} 1, \mathrm{~b} 1, \mathrm{c} 1, \mathrm{~d} 1)$, phospho-Tau $(12 \mathrm{E} 8, \mathrm{a} 2, \mathrm{~b} 2, \mathrm{c} 2, \mathrm{~d} 2)$ and merged $(\mathrm{a} 3, \mathrm{~b} 3, \mathrm{c} 3, \mathrm{~d} 3)$ pictures are depicted. (a1) No 12E8-immunoreactivity is present in control slices at DIV5 (a1-a3) and DIV10 (c1-c3). (b1) In contrast, in pro-aggregant slices 12E8-immunoreactivity is observed in pyramidal cell somata and dendrites at DIV5 (b1-b3) and DIV10 (d1-d3). (c4-c6) Zoom-in images (from (c1)) showing mossy fiber boutons filled with Tau. No 12E8 phosphorylation was detected in control slices. (d4-d6, zoom-in from d1) In contrast, boutons in pro-aggregant slices contain phosphorylated Tau. (c7-c9+ d7-d9) Immunostaining against pan-Tau (green), synaptophysin (S'physin, red) and merged picture is shown in control (c7-c9) and pro-aggregant slices (d7-d9). Arrows mark the axon shaft; boutons are marked by dotted line. (e) Higher magnification of single mossy fiber boutons (stained with Dil) in slices from control mice, pro-aggregant mice and pro-aggregant slices treated with compound bb14. (f) The bouton diameter was increased by $\sim 42 \%$ in pro-aggregant slices in comparison to control and by only 18\% when compared to bb14-treated pro-aggregant slices. (g) The bouton surface was larger in pro-aggregant slices (by 75\%) vs. control and by only 32\% vs. bb14-treated pro-aggregant slice cultures. (h) The average distance between boutons was increased by $\sim 50 \%$ in pro-aggregant slices compared to control and bb14-treated pro-aggregant cultures. (i) Numbers of filopodia (control: 1.56; pro-aggregant: 1.89; pro-aggregant + bb14: 1.77) per bouton was only slightly affected in pro-aggregant slices. (j) The length of filopodia (control: $1.66 \mu \mathrm{m}$; pro-aggregant: $1.39 \mu \mathrm{m}$; pro-aggregant + bb14: 1.69 $\mu \mathrm{m}$ ) was not changed in pro-aggregant slices. One way ANOVA followed by Tukey's post-hoc test ${ }^{* * *} p$ - value $<0.001 ;{ }^{*} p$-value $\left.<0.05\right)$. Error bars represent SEM.

firefly luciferase (Figure 8f-i) [29]. Induction of proaggregant $\mathrm{Tau}^{\mathrm{RD} \Delta}$ expression by doxycycline led to stable expression of the construct, tested via bioluminescence (data not shown). After 4 days of expression $\sim 5 \%$ of the cells developed Tau aggregates, which was visualized by Thioflavine-S (ThS) fluorescence (Figure $8 \mathrm{~g}$ and $\mathrm{h}$ ). N2a cells expressing pro-aggregant $\mathrm{Tau}^{\mathrm{RD} \Delta}$ displayed a severely reduced $\mathrm{KCl}$ induced $\mathrm{Ca}^{++}$influx $(-222 \%)$ compared to non-induced control cells, even before aggregates became detectable (pro-aggregant $\mathrm{Tau}^{\mathrm{RD} \Delta}$ : $370.4 \pm$ $26 \%$ of baseline, $\mathrm{n}=16$; non-induced control cells: $592.07 \pm 42 \%$ of baseline, $\mathrm{n}=38$, t-test $\mathrm{p}<0.0017$; Figure 8 i). This effect of pro-aggregant $\mathrm{Tau}^{\mathrm{RD} \Delta}$ was almost doubled $(-436 \%)$ in N2a cells with ThS detectable 


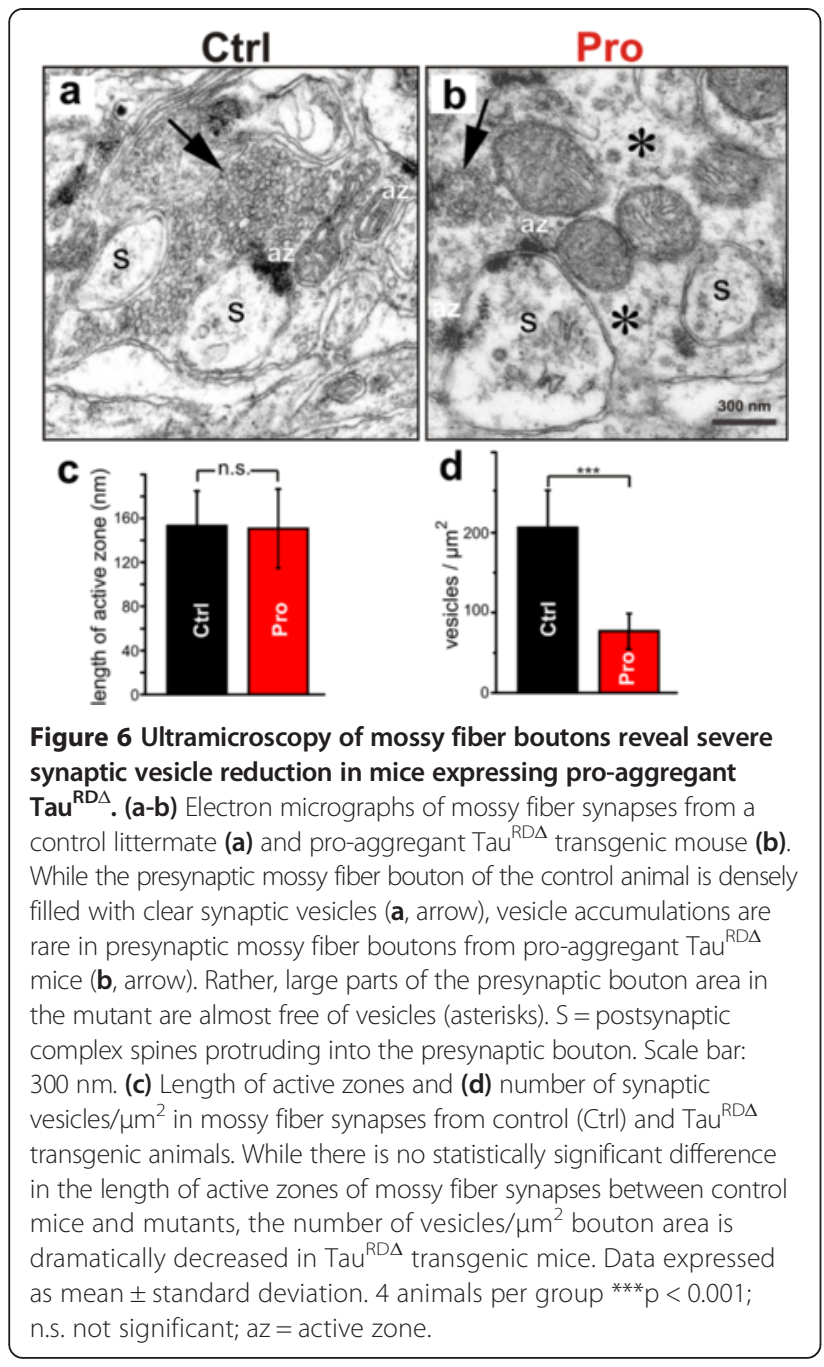

tangle load ( $156.83 \pm 8 \%$ of baseline; Figure $8 \mathrm{~h}, \mathrm{i})$. As an additional control we performed experiments with N2a cells expressing anti-aggregant $\mathrm{Tau}^{\mathrm{RD} \Delta \mathrm{PP}}$, in which evoked $\mathrm{Ca}^{++}$influx was not different from non-induced control cells $(657.08 \pm 28 \%$ of baseline, $n=60$; Figure $8 i)$.

We conclude that the pathophysiological effect of Tau is tightly coupled to its propensity for aggregation.

\section{Discussion}

Several authors have investigated the influence of pathological Tau on electrophysiological parameters in the hippocampus of transgenic mice. So far these studies were focused on postsynaptic functions in area CA1 $[4,6,42,43]$. However, in mature neurons Tau is largely restricted to axons, suggesting a presynaptic role $[44,45]$. In the present study we therefore focused on the physiological and pathophysiological role of axonal Tau and the impact of Tau aggregation on presynaptic morphology and function.

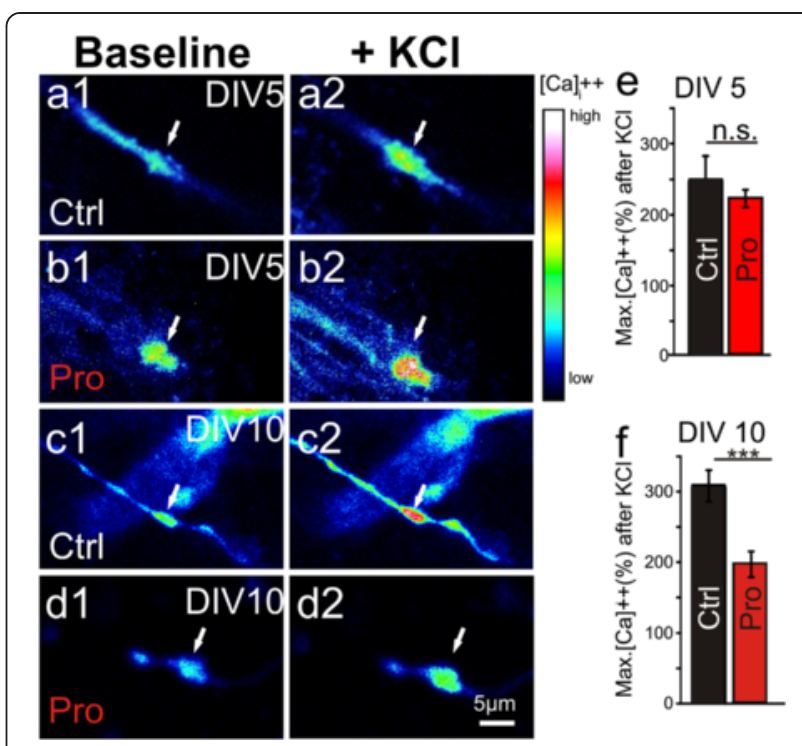

Figure 7 Progressive impairment of $\mathrm{Ca}^{++}$regulation in mossy fiber boutons in slices of $\mathrm{Tau}^{\mathrm{RD} \Delta}$. (a1) The photomicrograph shows a magnification of stratum lucidum in a hippocampal slice culture from a control mouse. The slice was labeled with the $\mathrm{Ca}^{++}$indicator dye Oregon Green BAPTA-1-AM (OGB-1) at DIV 5. After labeling it was possible to locate "giant" mossy fiber boutons loaded with OGB (white arrow). (a2) After membrane depolarization with high $\mathrm{KCl} \mathrm{Ca}^{++}$is flowing into the bouton (white arrow). The increase of intracellular calcium is false-color coded as indicated on the right column. (b1) Analogue to (a1-2) a bouton (white arrow) in a pro-aggregant slice is depicted before and after (b2) membrane depolarization (white arrow). (c1) At DIV 10 a stronger $\mathrm{Ca}^{++}$influx in boutons (white arrow) after membrane depolarization (c2) compared to boutons in DIV 5 slices (a1-a2) was observed. (d1) A strong decrease in $\mathrm{Ca}++$ influx after depolarization (d2) is observed in boutons from pro-aggregant Tau ${ }^{\mathrm{RD} \Delta}$ slices compared to control slices at DIV 10. (e) Quantification of maximum intracellular $\mathrm{Ca}^{++}$increase after high $\mathrm{KCl}$ application in mossy fiber boutons from control littermate slices (white column) and from pro-aggregant Tau ${ }^{\mathrm{RD} \Delta}$ slices (red column) at DIV 5. Note that the maximum intracellular $\mathrm{Ca}^{++}$concentration did not change in comparison to boutons from control littermate DIV 5 slices. (f) Comparison of maximum intracellular $\mathrm{Ca}^{++}$concentration in boutons from control littermate slices (white column) and from pro-aggregant Tau ${ }^{\mathrm{RD} \Delta}$ slices (red column) at DIV10. At DIV 10 the pro-aggregant Tau ${ }^{\mathrm{RD} \Delta}$ slices show a severe impairment in $\mathrm{Ca}^{++}$influx after membrane depolarization. Note that the maximum intracellular $\mathrm{Ca}^{++}$peak in control boutons increases with maturation of slices (compare e and $\mathrm{f}$ control). Error bars represent SEM. ${ }^{* * *} \mathrm{p}$-value $<0.001$.

The Tau mutation $\Delta \mathrm{K} 280$ was first described in a patient with FTDP-17 [46] and later in a case of Alzheimer disease [47]. The mutation affects Tau splicing and is unusual in that it enhances the fraction of 3R-Tau (where repeat R2 is excluded) compared to 4R-Tau, in contrast to many other mutations where 4-R Tau is enhanced. In theory, the mutation of the exon splicer enhancer element in exon 10 would be expected to cause complete exclusion of repeat R2 so that there would be no protein containing the $\Delta \mathrm{K} 280$ mutation [48], but in the patients a substantial amount of 4R-Tau with the 


\section{Primary hippocampal cell culture}
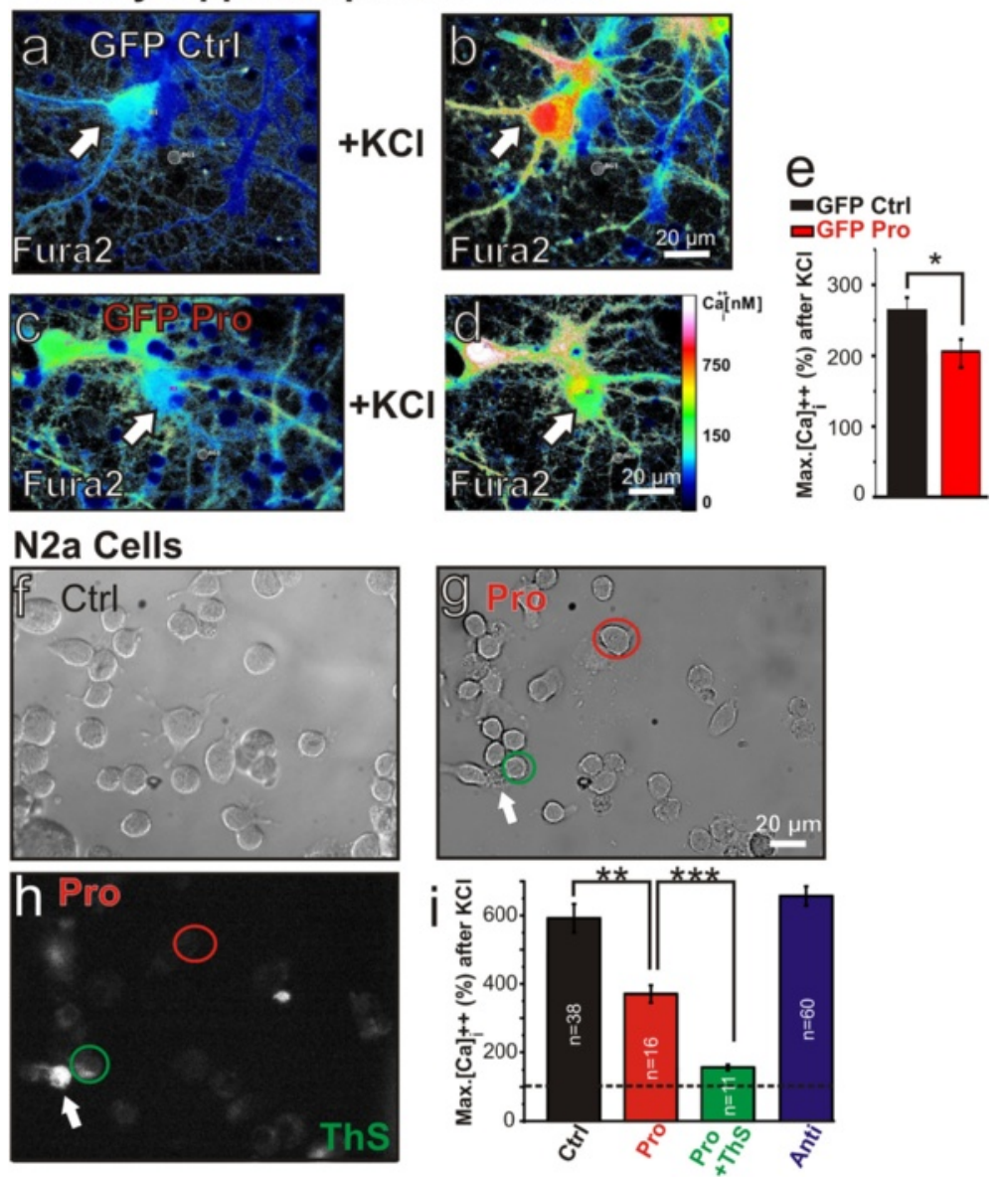

Figure 8 Expression of pro-aggregant $\mathrm{Tau}^{\mathrm{RD} \Delta}$ impairs $\mathrm{Ca}^{++}$regulation in primary hippocampal cell culture and N2a cells. (a) Intracellular $\mathrm{Ca}^{++}$concentrations in primary hippocampal cell culture transfected with GFP only (white arrow) before membrane depolarization by high $\mathrm{KCl}$. $\mathrm{Ca}^{++}$levels are depicted by false color coding according to Fura2 intensity (scale bar in (d)). (b) Same neuron as in (a) after high KCl stimulation. (c) Intracellular $\mathrm{Ca}^{++}$levels in a hippocampal neuron expressing pro-aggregant Tau ${ }^{\mathrm{RD} \Delta}$ and GFP (white arrow). (d) Same neuron as in (c) after membrane depolarization. (e) Quantification of $\mathrm{Ca}^{++}$imaging experiments demonstrating a reduction of calcium influx after high $\mathrm{KCl}$ application in pro-aggregant Tau ${ }^{\mathrm{RD} \Delta}$ expressing cells. Pictures in (a)-(d) are background subtracted at the indicated location (BG1). (f) Bright field image of a N2a control cell culture not expressing pro-aggregant $\operatorname{Tau}^{\mathrm{RD} \Delta}$. (g) Bright field image of a N2a cell culture expressing pro-aggregant Tau ${ }^{\mathrm{RD} \Delta}$. (h) Post-hoc staining after $\mathrm{Ca}^{++}$imaging experiment of the same cells as in (g) by washing in $0.0001 \%$ Thioflavines (ThS) for 5 minutes. ThS enables to distinguish between N2a cells expressing pro-aggregant Tau ${ }^{\mathrm{RD} \Delta}$ without neurofibrillary tangles (NFT, red circle), N2a cells with NFTs (green circle) and cells with NFT and destroyed membranes (white arrow). (i) Quantification of the maximum $\mathrm{Ca}^{++}$influx after $\mathrm{KCl}$ stimulation in N2a cells loaded with Fura2AM. Cell populations introduced in (f) and $(\mathbf{g})$ demonstrating that cells expressing pro-aggregant Tau ${ }^{\mathrm{RD} \Delta}$ with no ThS positive staining (pro; red column) are already severely impaired but cells with visible tangle load (pro + ThS, green column) are more impaired in Ca ${ }^{++}$ influx. N2a cells expressing anti-aggregant Tau ${ }^{\mathrm{RD} \Delta \mathrm{PP}}$ (anti, blue column) do not show reduced calcium influx compared to control cells. Values represent at least three independent experiments. Error bars represent SEM. ${ }^{*} p$-value $<0.05 ;{ }^{* *} p$-value $<0.01 ;{ }^{* * *} p$ - value $<0.001$.

$\Delta \mathrm{K} 280$ mutation is present in the hippocampus and cortex [47]. Since the mutant protein has a much greater propensity for aggregation compared to wild type Tau [49], and since Tau aggregation is a nucleationdependent process, nuclei formed by $\Delta K 280$ Tau could be elongated even from the pool of normal endogenous Tau and thus poison the entire Tau population [8]. Thus even a small amount of $4 \mathrm{R}$-Tau would be sufficient to initiate pathophysiological events (gain of toxic function). The toxic potential of the mutation is supported by cell and animal models with anti-aggregant Tau (where the propensity for $ß$-structure is eliminated by insertion of prolines). Mice expressing anti-aggregant $\mathrm{Tau}^{\mathrm{RD} \Delta \mathrm{PP}}$ show some weak Tau phosphorylation and mislocalization as well as slightly reduced frequency facilitation in the mossy fiber pathway $[7,8]$. But overall these changes are not sufficient to cause a behavioral phenotype in these mice. Alterations are likely due to an increase in the overall Tau level which may disturb the balance of kinases/phosphatases in the neuron as 
described previously [50]. In previous studies of the Tau$\Delta \mathrm{K} 280$ mutation we had noticed pronounced aggregation, but it was not clear in what pathway the major effect of mutant Tau was located. Here we demonstrate that it is the mossy fiber pathway in the hippocampus that is pronouncedly affected by degeneration. We describe a specific impairment of morphology of Taucontaining presynaptic mossy fiber boutons, which corresponds to an impaired synapse physiology and plasticity. Pronounced pathological phosphorylation, aggregation and missorting occurs in area CA3 in aged mice expressing pro-aggregant $\mathrm{Tau}{ }^{\mathrm{RD} \Delta}$, particularly in the stratum lucidum. Tau becomes enriched in mossy fiber giant boutons and reveals the pathognomonic MC-1 epitope in axons and presynapses, arguing for misconformational Tau in the mossy fiber presynapse due to co-aggregation of mutant and endogenous Tau. The mossy fiber boutons displayed a pathological increase of size, observable both in middle- aged mouse brains and in organotypic slices.

The organotypic slice model was further used to analyze the presynaptic structural changes in detail. Giant boutons on granule cell axons were spaced further apart in slices from pro-aggregant $\mathrm{Tau}{ }^{\mathrm{RD} \Delta}$ mice, and at the same time the bouton diameter and 3D surface became larger $(\sim 74 \%)$. This corresponds to a "condensed presynapse" pathological phenotype when considering the granule cell axon as a whole. We found less but bigger mossy fiber boutons at such axons. Taken together, the excitatory drive of granule cells is decreased due to "condensed presynapses" in pro-aggregant mice, which is reflected in a severely reduced basal synaptic transmission. By contrast, in anti-aggregant animals there was no impairment in basal synaptic transmission or in bouton diameter although endogenous Tau became phosphorylated at AT8 and AT180 site. Looking at the inhibitory site of transmission, we found that filipodia which are known to innervate inhibitory interneurons were slightly increased in number but decreased in length which could account for a compensatory effect. We conclude that aggregation-prone Tau is causal for the reduction in synaptic transmission at the mf-CA3 synapse. Consistent with this, treatment with the aggregation inhibitor bb14 [31] prevented pathological preand postsynaptic morphological changes in area CA3 of pro-aggregant $\mathrm{Tau}{ }^{\mathrm{RD} \Delta}$ slices. Data from organotypic slice cultures enabled us to present a comparison of pathological effects on postsynaptic structures (loss of dendritic spines in area CA3:-20\%) and the effect of pro-aggregant $\mathrm{Tau}^{\mathrm{RD} \Delta}$ on the presynapse-site (bouton diameter increase: $+42 \%)$ in parallel. Moreover ultrastructural analysis demonstrated severe reduction of vesicle density in the pathologically modified mossy fiber boutons. Although we cannot rule out the possibility that reduced vesicle density is simply due to an increase in bouton size the finding correlates well with the dramatic effect of proaggregant $\mathrm{Tau}^{\mathrm{RD} \Delta}$ on basal synaptic transmission of the mossy fiber pathway (Figure 2a).

Unexpectedly, the depletion of Tau in the TKO mice [25] also led to a pronounced increase in bouton diameter and a concomitant reduction in basal synaptic transmission (Figure 2a), comparable to the phenotype observed in pro-aggregant mice. In pro-aggregant mice, it is likely that an accumulation of aggregating Tau (as visualized by $\mathrm{MC1}$ antibody) in presynaptic terminals leads to an overall increase of the mossy fiber bouton diameter. In contrast, the phenotype observed in TKO mice is more ambiguous. A role of Tau during axon growth and maturation [51] was previously described and primary neurons obtained from the Tau knockout strain showed reduced axon length [25]. This illustrates that Tau reduction can cause structural changes in axons. Why this does not lead to impairment in synaptic plasticity at 13 months remains to be investigated. Nevertheless, the reduction of basal synaptic transmission in the mossy fiber pathway implies a physiological role of Tau as a regulator of neuronal excitability at the DG-CA3 synapse. This might in turn explain how a genetic reduction of Tau could lead to a reduction of seizure susceptibility in hAPP mouse models when crossed with TKO mice [52] and even in non-AD related epilepsy models $[53,54]$. It has been speculated that the dentate gyrus might act as a "shield" protecting from spreading of epileptiform activity from cortical regions into the hippocampus because of the low intrinsic excitability of dentate granule cells compared with pyramidal cells $[55,56]$. On the basis of this hypothesis increased seizure susceptibility in hAPP models would be ameliorated by decreased synaptic transmission at the DG-CA3 synapse due to Tau depletion.

Since we did not detect any plasticity impairments in our TKO mice at the mossy fiber-CA3 synapse we conclude that Tau reduction at that synapse could counteract hyperexcitability effects in hAPP mouse models without affecting learning and memory. However a recent study reports plasticity deficits in a different experimental paradigm due to Tau reduction [57], but in contrast to our study deficiencies were found in area CA1.

Subsequently to synaptic transmission we measured mossy fiber short-term plasticity (by paired pulse facilitation and frequency facilitation) and long-term depression (by low frequency stimulation). In contrast to the results on basal synaptic transmission we found that endogenous Tau was indeed not essential for normal mossy fiber short-term plasticity and long-term depression in the mossy fiber pathway. TKO mice were indistinguishable from controls in both parameters in spite of the pathological mossy fiber bouton size increase. However, 
in middle-aged pro-aggregant mice we observed reduced paired pulse facilitation, frequency facilitation and disrupted LTD expression. This phenotype of impaired mfplasticity was not present in 2 month-old mice expressing pro-aggregant $\mathrm{Tau}^{\mathrm{RD} \Delta}$ confiming a "phenotype progression" in our mouse model. Paired pulse facilitation is known to depend on presynaptic calcium dynamics [58]. In $A D$ patients a colocalization of $A 1$ receptors with $A ß$ plaques and with tangle bearing pyramidal cells in the hippocampus has been described [59]. Moreover the activation of A1 receptors led to the phosphorylation of Tau and its translocation towards particulate fractions from SH-SY5Y neuroblastoma cells [59]. Given that frequency facilitation is closely correlated with LTD [60] in vivo and since proper A1 receptor function is essential for mossy fiber plasticity [20], any modifications of A1 receptor function or transport inhibition might partly contribute to reduced basal synaptic transmission, reduced frequency facilitation and impaired LTD in pro-aggregant animals.

Since the mossy fiber synapse is essential for memory recall, storage and pattern completion [61,62], the described loss of plasticity at this synapse should have deleterious consequences on memory and cognition. This assumption is consistent with previous behavioral observations $[7,8]$ and should therefore be extended in future studies to mossy fiber specific pattern-separation behavioral tests [63].

The major and general cellular prerequisite for bidirectional plasticity is an intact $\mathrm{Ca}^{++}$homeostasis and activity-dependent $\mathrm{Ca}^{++}$influx [64-66]. In particular, at the $\mathrm{mf}$ synapse an activity-dependent rise in $\mathrm{Ca}^{++}$levels is necessary for proper LTD expression [23]. We detected a strong reduction of $\mathrm{Ca}^{++}$influx after membrane depolarization at the mossy fiber presynapse, which argues that this is the reason for the pathophysiological effect of $\mathrm{Tau}^{\mathrm{RD} \Delta}$ on presynaptic plasticity. Notably this effect occurs at a time point (DIV 10) where no tangles are present in organotypic slices from pro-aggregant mice, suggesting a soluble, "pre-tangle" form of aggregating Tau that is sufficient for this pathological effect. At an earlier time point (DIV 5) there was only a slight decrease in $\mathrm{Ca}^{++}$influx which underscores that there is a pathological progression in the slice model system. Similarly, two previous studies reported early presynaptic deficits in the enthorinal cortex of Tau transgenic mice $[67,68]$. Using primary hippocampal cell culture, we found that pro-aggregant $\mathrm{Tau}^{\mathrm{RD} \Delta}$ also led to severe attenuation of $\mathrm{Ca}^{++}$influx in the soma of transiently transfected neurons. This was true even in the absence of Tau aggregates. To investigate if this effect is exacerbated by Tau aggregates, we next used inducible N2a cells expressing the same pro-aggregant $\mathrm{Tau}^{\mathrm{RD} \Delta}$. N2a cells display a prominent $\mathrm{Ca}^{++}$influx mediated by L-type voltage-gated calcium channels (VGCC) as a response to membrane depolarization [69]. Like the primary hippocampal neurons, the N2a cells showed a reduction of $\mathrm{Ca}^{++}$influx due to pro-aggregant $\mathrm{Tau}{ }^{\mathrm{RD} \Delta}$, even before the appearance of ThS-stained Tau aggregates. This effect occurs only with pro-aggregant but not with antiaggregant $\mathrm{Tau}{ }^{\mathrm{RD}} \Delta \mathrm{PP}$ and may be explained again by "pre-tangle" oligomeric aggregates which are known to impair cognition in transgenic Tau mice before fullblown tangles appear $[9,70,71]$. Interestingly, in N2a cells the impairment of $\mathrm{Ca}^{++}$influx was further worsened when ThS-positive Tau aggregates appeared intracellularly. This leads us to propose the activity dependent dysfunction in neuronal $\mathrm{Ca}^{++}$regulation as a cellular patho-mechanism of the observed pre-and postsynaptic tauopathy phenotypes.

\section{Conclusions}

In summary we suggest that the pathophysiological effects of pro-aggregant $\mathrm{Tau}^{\mathrm{RD} \Delta}$ on calcium influx and the reduction of synaptic vesicle density causes the impairment of transmission and presynaptic plasticity at the mf-synapse, which will in turn lead to behavioral and cognitive deficits in $\mathrm{AD}$ and other tauopathies (Additional file 6: Figure S4).

\section{Additional files}

Additional file 1: Supplemental experimental procedures.

Additional file 2: Table S1. Summary of Tau antibodies.

Additional file 3: Figure S1. Mossy fibers are positive for Tauopathy markers detected by immunofluorescence in 13 months old Tau ${ }^{\mathrm{RD} \Delta}$ mice. (a) Microphotograph of area CA3 showing that there is no detectable PHF-1 immunoreactivity in control littermate mice (Ctrl). (b) In area CA3 of Tau ${ }^{\mathrm{RD} \Delta}$ expressing mice (Pro) Tau phosphorylation detected by PHF1 immunoreactivity is observed in the mossy fiber pathway (white arrow) in a dotted pattern. (c) Control littermate mice (Ctrl) do not show any AT-8 immunoreactivity in area CA3. (d) Mice expressing Tau ${ }^{\mathrm{RD} \Delta}$ (Pro) show AT-8 immunoreactivity in area CA3. (e) PHF1 staining displays phosphorylated Tau within the entire lengths of the mossy fibers in pro-aggregant mice (Pro). White arrows indicate weakly stained granule cells in the dentate gyrus.

Additional file 4: Figure S2. Expression of exogenous pro- or anti-aggregant $\mathrm{Tau}{ }^{\mathrm{RD} \Delta}$ results in phosphorylation of endogenous mouse Tau and alterations of post- and presynaptic protein levels of the hippocampus. (a) Representative expression of human Tau ${ }^{\mathrm{RD}}$ (Mr $\sim 12-14$ kDa) and endogenous mouse Tau (mTau, Mr $\sim 45-55 \mathrm{kDa}$ ) in pro- and anti-aggregant Tau ${ }^{\mathrm{RD}}$ mice compared to control and Tau knockout (TKO) mice. Visualization of non-phosphorylated human and mouse Tau by the pan-Tau antibody K9JA. (b/c) Phosphorylated mouse Tau is only detected in hippocampus homogenates of pro-and anti-aggregant mice by phosphorylation-dependent antibodies AT180 (pT231/pSer235) (b) and AT8 (pSer202/pThr205) (c). (d) Conformational dependent MC-1 immunoreactivity was detected in somata of pyramidal cells in stratum pyramidale of area CA3 and stratum lucidum (asterisk) in pro-aggregant $\mathrm{Tau}^{\mathrm{RD} \Delta}$ mice, but not in control littermates (Ctrl). (e) Representative levels of postsynaptic proteins (PSD95, NMDAR1) and presynaptic proteins (synaptophysin (S'physin), synapsin 1 and piccolo) of CA3 lysates from control, pro- and anti-aggregant and TKO mice. ß-actin serves as loading control. (f) Bars show densiometric analysis of the Western blots (e) for the synaptic proteins (PSD95, NMDAR1, synaptophysin, synapsin 1), all normalized to $ß$-actin $(n=4)$. The red (pro-aggregant $\operatorname{Tau}^{\mathrm{RD} \Delta}$ ) and green (anti-aggregant Tau ${ }^{\mathrm{RD} \Delta \mathrm{PP}}$ ) bars indicate the alteration of the 
synaptic levels within these mouse strains compared to WT (gray) and TKO (blue) mice. In the pro-aggregant mice the majority of synaptic proteins is reduced (between 60-90\% of control level), but the synaptic proteins in the anti-aggregant and TKO mice show similar or higher expression levels than WT mice. Bars represent mean \pm SEM.

Additional file 5: Figure S3. Axonal and presynaptic localization of Tau and missorting to postsynaptic compartments due to pro-aggregant $\operatorname{Tau}^{\mathrm{RD} \Delta}$ expression. (a) Example of immunohistological detection of endogenous mouse Tau with pan-Tau antibody (K9JA) in stratum lucidum of area CA3 b-c of the hippocampus in a control littermate mouse at $13 \pm 1$ month. Note that strong immunoreactivity (white color) is seen exclusively in the stratum lucidum (s.l., dashed line), where mossy fiber axonal fibers from the dentate gyrus granule cells innervate apical dendrites of CA3 pyramidal cells. Cell somata and dendrites of pyramidal cells are not Tau immunoreactive (note the black "shadows" of non- immunoreactive cell bodies (green arrows) and apical dendrites; s.p. = stratum pyramidale; s.r. = stratum radiatum) (b) Immunoreactivity against endogenous and exogenous Tau in area CA3 of the hippocampus of pro-aggregant (Pro) Tau mice. Tau gets missorted into the somato-dendritic compartment. Strong immunoreactivity (white color) is seen in cell bodies of s.p. in axonal structures in s.l. and in s.r. Arrows point at a pyramidal nucleus (green), an apical dendrite (orange), and mossy fiber bundles in s.l. of area CA3 b-c (dashed line). (c) Control littermate slice (Ctrl) from 13 month old mice stained with a pan-Tau antibody. A region in stratum lucidum was magnified in order to show Tau containing mossy fiber presynapse (bouton; highlighted by white dotted circle). (d) Dil labeling (red) of the same region showing the morphology of a "giant" mossy fiber bouton (white dotted circle). (e) Merged picture from (c) and (d) pointing at a "giant" mossy fiber bouton containing Tau (white arrow). (f) K9JA immunoreactivity in the region of the hilus (CA3C) of a pro-aggregant animal (Pro) at the same age as in (c) showing Tau in a "giant" bouton (white dotted circle). Mislocalized, dendritic Tau is indicated by a white arrow. (g) Dil labeling of the same region as in (f) is showing a bouton (white dotted circle) and a neighboring dendrite (white arrow). (h) Merge of picture ( $f$ ) and (g) showing co-localization of Dil labeling and Tau immunoreactivity.

Additional file 6: Figure S4. Schematic illustration of the chain of events leading to synaptic plasticity breakdown due to the aggregation of Tau. In a first step Tau aggregation and phosphorylation lead to a reduced intracellular calcium influx after activity induction. This immediate effect on cellular calcium dynamics is hypothesized to lead to pre-and postsynaptic structural and functional changes. On the presynaptic side aggregation-prone Tau leads to fewer but larger boutons per axon, a net loss of presynaptic markers and to a reduced number of synaptic vesicles finally resulting in a decrease of basal synaptic transmission and short-term plasticity. On the postsynaptic side the dendritic spine density and the important scaffold protein PSD95 are reduced. This - together with presynaptic deficits - is responsible for the deleterious effect of Tau aggregation on long term depression (LTD) of the mossy fiber-CA3 synapse.

\section{Abbreviations}

AD: Alzheimer disease; anti-aggregant $\mathrm{Tau}^{\mathrm{RD} \Delta \mathrm{PP}}=\mathrm{Tau}^{\mathrm{RD}} \Delta \mathrm{K} 280 \mathrm{PP}$ : Tau repeat domain with mutation $\triangle \mathrm{K} 280$ and two additional prolines; CA: Cornu ammonis; $\mathrm{Ca}^{++}$: Calcium; DG: Dentate gyrus; FTDP-17: Frontotemporal dementia with parkinsonism linked to chromosome-17; LFS: Low frequency stimulation; LTD: Long term depression; Mf: Mossy fiber; pro-aggregant $\operatorname{Tau}^{\mathrm{RD} \Delta}=\mathrm{Tau}^{\mathrm{RD}} \Delta \mathrm{K} 280$ : Tau repeat domain with mutation $\Delta K 280$; TKO: Tau knockout strain.

\section{Competing interests}

The authors declare that they have no competing interests.

\section{Authors' contributions}

JMD performed acute hippocampal slice preparation, electrophysiology, calcium imaging experiments, structural analysis and immunohistofluorescence experiments. LK prepared organotypic hippocampal slices and performed calcium imaging experiments, structural analysis and immunohistofluorescence in organtotypic slices. AS performed immunohistochemistry and biochemistry from adult mouse brains. SZ and
MF performed electron microscopy and evaluation. JMD, E and E-MM wrote the manuscript. All authors read and approved the final manuscript.

\section{Acknowledgements}

We thank the following lab members for their expert help and advice: Olga Petrova and Anne Hofmann (Hamburg) for help with some of the brain sections and biochemical analysis; Julia Lüdtke (Bonn) for preparation of hippocampal cell cultures, Stefanie Koenen (Bonn) for help with statistical analysis, Dr. Katja Hochgräfe (Hamburg) for monitoring gene expression by bioluminescence, Dr. Marcus Pickhardt and Dr. Jacek Biernat (Bonn) for help with N2a cell-lines, Dr. Marcus Pickhardt (DZNE) and Dr. Bruno Bulic (Humboldt University, Berlin) for aggregation inhibitor compound bb14. We owe special thanks to Dr. Andreas Haemisch and his team at the animal facility at the University of Hamburg Medical School for their continuous help in mouse breeding. Furthermore we thank the team of the animal facility of Caesar (headed by Dr. Dagmar Wachten) and the team of the animal facility of DZNE Bonn (headed by Dr. Ylva Mende \& Dr. Michaela Möhring). Reagents are gratefully acknowledged from Prof. Dr. E. Kandel (Columbia University, New York, NY; CaMKIlla-tTA transgenic mice), Dr. P. Seubert (Elan Pharma, South San Francisco, CA; 12E8 antibody), and Dr. Hana Dawson for generously providing the Tau KO mice. This research was supported by MPG, DZNE, Wellcome Trust/MRC and Tau consortium. MF is Senior Research Professor supported by the Hertie Foundation.

\section{Author details}

'German Center for Neurodegenerative Diseases (DZNE), Ludwig-Erhard-Allee 2, 53175 Bonn, Germany. ${ }^{2}$ Caesar Research Center, Ludwig-Erhard-Allee 2, 53175 Bonn, Germany. ${ }^{3}$ Max-Planck-Institute for Metabolism Research, Hamburg Outstation, c/o DESY, Notkestrasse 85, 22607 Hamburg, Germany. ${ }^{4}$ University Medical Center Hamburg-Eppendorf, Center for Molecular Neurobiology Hamburg, Institute for Structural Neurobiology, Falkenried 94, 20251 Hamburg, Germany.

Received: 30 January 2015 Accepted: 3 February 2015 Published online: 03 April 2015

\section{References}

1. Selkoe D, Mandelkow E, Holtzman D (2012) Deciphering Alzheimer disease. Cold Spring Harb Perspect Med 2(1):a011460

2. Josephs KA, Hodges JR, Snowden JS, Mackenzie IR, Neumann M, Mann DM, Dickson DW (2011) Neuropathological background of phenotypical variability in frontotemporal dementia. Acta Neuropathol 122(2):137-153

3. Braak H, Braak E (1991) Neuropathological stageing of Alzheimer-related changes. Acta Neuropathol 82(4):239-259

4. Ittner $L M$, Ke YD, Delerue F, Bi M, Gladbach A, van Eersel J, Wolfing $H$, Chieng BC, Christie MJ, Napier IA, Eckert A, Staufenbiel M, Hardeman E, Gotz $J$ (2010) Dendritic function of tau mediates amyloid-beta toxicity in Alzheimer's disease mouse models. Cell 142(3):387-397

5. Hoover BR, Reed MN, Su J, Penrod RD, Kotilinek LA, Grant MK, Pitstick R, Carlson GA, Lanier LM, Yuan LL, Ashe KH, Liao D (2010) Tau mislocalization to dendritic spines mediates synaptic dysfunction independently of neurodegeneration. Neuron 68(6):1067-1081

6. Van der Jeugd A, Ahmed T, Burnouf S, Belarbi K, Hamdame M, Grosjean ME, Humez S, Balschun D, Blum D, Buee L, D'Hooge R (2011) Hippocampal tauopathy in tau transgenic mice coincides with impaired hippocampusdependent learning and memory, and attenuated late-phase long-term depression of synaptic transmission. Neurobiol Learn Mem 95(3):296-304

7. Sydow A, Van der Jeugd A, Zheng F, Ahmed T, Balschun D, Petrova O, Drexler D, Zhou L, Rune G, Mandelkow E, D'Hooge R, Alzheimer C, Mandelkow EM (2011) Tau-induced defects in synaptic plasticity, learning, and memory are reversible in transgenic mice after switching off the toxic Tau mutant. J Neurosci 31(7):2511-2525

8. Mocanu MM, Nissen A, Eckermann K, Khlistunova I, Biernat J, Drexler D, Petrova O, Schonig K, Bujard H, Mandelkow E, Zhou L, Rune G, Mandelkow EM (2008) The potential for beta-structure in the repeat domain of tau protein determines aggregation, synaptic decay, neuronal loss, and coassembly with endogenous Tau in inducible mouse models of tauopathy. J Neurosci 28(3):737-748

9. Van der Jeugd A, Hochgrafe K, Ahmed T, Decker JM, Sydow A, Hofmann A, Wu D, Messing L, Balschun D, D'Hooge R, Mandelkow EM (2012) Cognitive 
defects are reversible in inducible mice expressing pro-aggregant full-length human Tau. Acta Neuropathol 123(6):787-805

10. Braak H, Alafuzoff I, Arzberger T, Kretzschmar H, Del Tredici K (2006) Staging of Alzheimer disease-associated neurofibrillary pathology using paraffin sections and immunocytochemistry. Acta Neuropathol 112(4):389-404

11. Blazquez-Llorca L, Garcia-Marin V, Merino-Serrais P, Avila J, DeFelipe J (2011) Abnormal tau phosphorylation in the thorny excrescences of CA3 hippocampal neurons in patients with Alzheimer's disease. J Alzheimers Dis 26(4):683-698

12. Tsamis IK, Mytilinaios GD, Njau NS, Fotiou FD, Glaftsi S, Costa V, Baloyannis JS (2010) Properties of CA3 dendritic excrescences in Alzheimer's disease. Curr Alzheimer Res 7(1):84-90

13. Dickson DW, Yen SH, Horoupian DS (1986) Pick body-like inclusions in the dentate fascia of the hippocampus in Alzheimer's disease. Acta Neuropathol 71(1-2):38-45

14. Brady DR, Mufson EJ (1991) Alz-50 immunoreactive neuropil differentiates hippocampal complex subfields in Alzheimer's disease. J Comp Neurol 305 (3):489-507

15. Wakabayashi K, Hansen LA, Vincent I, Mallory M, Masliah E (1997) Neurofibrillary tangles in the dentate granule cells of patients with Alzheimer's disease, Lewy body disease and progressive supranuclear palsy. Acta Neuropathol 93(1):7-12

16. Arendt T, Stieler J, Strijkstra AM, Hut RA, Rudiger J, Van der Zee EA, Harkany T, Holzer M, Hartig W (2003) Reversible paired helical filament-like phosphorylation of tau is an adaptive process associated with neuronal plasticity in hibernating animals. J Neurosci 23(18):6972-6981

17. Holahan MR, Honegger KS, Routtenberg A (2007) Expansion and retraction of hippocampal mossy fibers during postweaning development: strainspecific effects of NMDA receptor blockade. Hippocampus 17(1):58-67

18. Pollard H, Khrestchatisky M, Moreau J, Ben-Ari Y, Represa A (1994) Correlation between reactive sprouting and microtubule protein expression in epileptic hippocampus. Neuroscience 61(4):773-787

19. Jonas P, Major G, Sakmann B (1993) Quantal components of unitary EPSCS at the mossy fibre synapse on CA3 pyramidal cells of rat hippocampus. J Physiol 472:615-663

20. Moore KA, Nicoll RA, Schmitz D (2003) Adenosine gates synaptic plasticity at hippocampal mossy fiber synapses. Proc Natl Acad Sci U S A 100(24):14397-14402

21. Kwon HB, Castillo PE (2008) Role of glutamate autoreceptors at hippocampal mossy fiber synapses. Neuron 60(6):1082-1094

22. Kobayashi K, Manabe T, Takahashi T (1996) Presynaptic long-term depression at the hippocampal mossy fiber-CA3 synapse. Science 273 (5275):648-650

23. Lyon L, Borel M, Carrion M, Kew JN, Corti C, Harrison PJ, Burnet PW, Paulsen O, Rodriguez-Moreno A (2011) Hippocampal mossy fiber long-term depression in Grm2/3 double knockout mice. Synapse 65(9):945-954

24. Hochgrafe K, Mandelkow EM (2013) Making the brain glow: in vivo bioluminescence imaging to study neurodegeneration. Mol Neurobiol 47 (3):868-882

25. Dawson HN, Ferreira A, Eyster MV, Ghoshal N, Binder LI, Vitek MP (2001) Inhibition of neuronal maturation in primary hippocampal neurons from tau deficient mice. J Cell Sci 114(Pt 6):1179-1187

26. Stoppini L, Buchs PA, Muller D (1991) A simple method for organotypic cultures of nervous tissue. J Neurosci Methods 37(2):173-182

27. Messing L, Decker JM, Joseph M, Mandelkow E, Mandelkow EM (2013) Cascade of tau toxicity in inducible hippocampal brain slices and prevention by aggregation inhibitors. Neurobiol Aging 34(5):1343-1354

28. Zempel H, Thies E, Mandelkow E, Mandelkow EM (2010) Abeta oligomers cause localized $\mathrm{Ca}(2+)$ elevation, missorting of endogenous Tau into dendrites, Tau phosphorylation, and destruction of microtubules and spines. J Neurosci 30(36):11938-11950

29. Khlistunova I, Biernat J, Wang Y, Pickhardt M, von Bergen M, Gazova Z, Mandelkow E, Mandelkow EM (2006) Inducible expression of Tau repeat domain in cell models of tauopathy: aggregation is toxic to cells but can be reversed by inhibitor drugs. J Biol Chem 281(2):1205-1214

30. Behrens CJ, van den Boom LP, de Hoz L, Friedman A, Heinemann U (2005) Induction of sharp wave-ripple complexes in vitro and reorganization of hippocampal networks. Nat Neurosci 8(11):1560-1567

31. Bulic B, Pickhardt M, Mandelkow EM, Mandelkow E (2010) Tau protein and tau aggregation inhibitors. Neuropharmacology 59(4-5):276-289

32. Pickhardt M, Gazova Z, von Bergen M, Khlistunova I, Wang Y, Hascher A, Mandelkow EM, Biernat J, Mandelkow E (2005) Anthraquinones inhibit tau aggregation and dissolve Alzheimer's paired helical filaments in vitro and in cells. J Biol Chem 280(5):3628-3635
33. Ksiezak-Reding H, Liu WK, Yen SH (1992) Phosphate analysis and dephosphorylation of modified tau associated with paired helical filaments. Brain Res 597(2):209-219

34. Kopke E, Tung YC, Shaikh S, Alonso AC, lqbal K, Grundke-labal I (1993) Microtubule-associated protein tau. Abnormal phosphorylation of a non-paired helical filament pool in Alzheimer disease. J Biol Chem 268(32):24374-24384

35. Dailey ME, Buchanan J, Bergles DE, Smith SJ (1994) Mossy fiber growth and synaptogenesis in rat hippocampal slices in vitro. J Neurosci 14(3 Pt 1):1060-1078

36. Frotscher M, Gahwiler BH (1988) Synaptic organization of intracellularly stained CA3 pyramidal neurons in slice cultures of rat hippocampus. Neuroscience 24(2):541-551

37. Zhao S, Studer D, Chai X, Graber W, Brose N, Nestel S, Young C, Rodriquez EP, Saetzler K, Frotscher M (2012) Structural plasticity of hippocampal mossy fiber synapses as revealed by high-pressure freezing. J Comp Neurol 520 (11):2340-2351

38. Gahwiler BH, Capogna M, Debanne D, McKinney RA, Thompson SM (1997) Organotypic slice cultures: a technique has come of age. Trends Neurosci 20(10):471-477

39. De Simoni A, Griesinger CB, Edwards FA (2003) Development of rat CA1 neurones in acute versus organotypic slices: role of experience in synaptic morphology and activity. J Physiol 550(Pt 1):135-147

40. Rollenhagen A, Lubke JH (2010) The mossy fiber bouton: the "common" or the "unique" synapse? Front Synaptic Neurosci 2:2

41. Flavell SW, Greenberg ME (2008) Signaling mechanisms linking neuronal activity to gene expression and plasticity of the nervous system. Annu Rev Neurosci 31:563-590

42. Schindowski K, Bretteville A, Leroy K, Begard S, Brion JP, Hamdane M, Buee $L$ (2006) Alzheimer's disease-like tau neuropathology leads to memory deficits and loss of functional synapses in a novel mutated tau transgenic mouse without any motor deficits. Am J Pathol 169(2):599-616

43. Burnouf S, Martire A, Derisbourg M, Laurent C, Belarbi K, Leboucher A, Fernandez-Gomez FJ, Troquier L, Eddarkaoui S, Grosjean ME, Demeyer D, Muhr-Tailleux A, Buisson A, Sergeant N, Hamdane M, Humez S, Popoli P, Buee L, Blum D (2013) NMDA receptor dysfunction contributes to impaired brain-derived neurotrophic factor-induced facilitation of hippocampal synaptic transmission in a Tau transgenic model. Aging Cell 12(1):11-23

44. Binder LI, Frankfurter A, Rebhun LI (1986) Differential localization of MAP-2 and tau in mammalian neurons in situ. Ann N Y Acad Sci 466:145-166

45. Kanai $Y$, Hirokawa N (1995) Sorting mechanisms of tau and MAP2 in neurons: suppressed axonal transit of MAP2 and locally regulated microtubule binding. Neuron 14(2):421-432

46. Rizzu P, Van Swieten JC, Joosse M, Hasegawa M, Stevens M, Tibben A, Niermeijer MF, Hillebrand M, Ravid R, Oostra BA, Goedert M, van Duijn CM, Heutink P (1999) High prevalence of mutations in the microtubuleassociated protein tau in a population study of frontotemporal dementia in the Netherlands. Am J Hum Genet 64(2):414-421

47. Momeni P, Pittman A, Lashley T, Vandrovcova J, Malzer E, Luk C, Hulette C, Lees A, Revesz T, Hardy J, de Silva R (2009) Clinical and pathological features of an Alzheimer's disease patient with the MAPT Delta K280 mutation. Neurobiol Aging 30(3):388-393

48. D'Souza I, Poorkaj P, Hong M, Nochlin D, Lee VM, Bird TD, Schellenberg GD (1999) Missense and silent tau gene mutations cause frontotemporal dementia with parkinsonism-chromosome 17 type, by affecting multiple alternative RNA splicing regulatory elements. Proc Natl Acad Sci U S A 96(10):5598-5603

49. Barghorn S, Zheng-Fischhofer Q, Ackmann M, Biernat J, von Bergen M, Mandelkow EM, Mandelkow E (2000) Structure, microtubule interactions, and paired helical filament aggregation by tau mutants of frontotemporal dementias. Biochemistry 39(38):11714-11721

50. Andorfer C, Kress Y, Espinoza M, de Silva R, Tucker KL, Barde YA, Duff K Davies $P$ (2003) Hyperphosphorylation and aggregation of tau in mice expressing normal human tau isoforms. J Neurochem 86(3):582-590

51. Caceres A, Kosik KS (1990) Inhibition of neurite polarity by tau antisense oligonucleotides in primary cerebellar neurons. Nature 343(6257):461-463

52. Roberson ED, Scearce-Levie K, Palop JJ, Yan F, Cheng IH, Wu T, Gerstein H, Yu GQ, Mucke L (2007) Reducing endogenous tau ameliorates amyloid beta-induced deficits in an Alzheimer's disease mouse model. Science 316 (5825):750-754

53. Devos SL, Goncharoff DK, Chen G, Kebodeaux CS, Yamada K, Stewart FR, Schuler DR, Maloney SE, Wozniak DF, Rigo F, Bennett CF, Cirrito JR, Holtzman DM, Miller TM (2013) Antisense Reduction of Tau in Adult Mice Protects against Seizures. J Neurosci 33(31):12887-12897 
54. Holth JK, Bomben VC, Reed JG, Inoue T, Younkin L, Younkin SG, Pautler RG, Botas J, Noebels JL (2013) Tau loss attenuates neuronal network hyperexcitability in mouse and Drosophila genetic models of epilepsy. $J$ Neurosci 33(4):1651-1659

55. Perlin JB, Churn SB, Lothman EW, DeLorenzo RJ (1992) Loss of type ॥ calcium/calmodulin-dependent kinase activity correlates with stages of development of electrographic seizures in status epilepticus in rat. Epilepsy Res 11(2):111-118

56. Bertram EH, Cornett J (1993) The ontogeny of seizures in a rat model of limbic epilepsy: evidence for a kindling process in the development of chronic spontaneous seizures. Brain Res 625(2):295-300

57. Kimura T, Whitcomb DJ, Jo J, Regan P, Piers T, Heo S, Brown C, Hashikawa T, Murayama M, Seok H, Sotiropoulos I, Kim E, Collingridge GL, Takashima A, Cho K (2014) Microtubule-associated protein tau is essential for long-term depression in the hippocampus. Philos Trans R Soc Lond B Biol Sci 369 (1633):20130144

58. Zucker RS, Regehr WG (2002) Short-term synaptic plasticity. Annu Rev Physiol 64:355-405

59. Angulo E, Casado V, Mallol J, Canela El, Vinals F, Ferrer I, Lluis C, Franco R (2003) A1 adenosine receptors accumulate in neurodegenerative structures in Alzheimer disease and mediate both amyloid precursor protein processing and tau phosphorylation and translocation. Brain Pathol 13(4):440-451

60. Hagena H, Manahan-Vaughan D (2010) Frequency facilitation at mossy fiber-CA3 synapses of freely behaving rats contributes to the induction of persistent LTD via an adenosine-A1 receptor-regulated mechanism. Cereb Cortex 20(5):1121-1130

61. Nakazawa K, Quirk MC, Chitwood RA, Watanabe M, Yeckel MF, Sun LD, Kato A, Carr CA, Johnston D, Wilson MA, Tonegawa S (2002) Requirement for hippocampal CA3 NMDA receptors in associative memory recall. Science 297(5579):211-218

62. Bischofberger J, Engel D, Li L, Geiger JR, Jonas P (2006) Patch-clamp recording from mossy fiber terminals in hippocampal slices. Nat Protoc 1 (4):2075-2081

63. Butler $G$, Rasmussen MD, Lin MF, Santos MA, Sakthikumar S, Munro CA, Rheinbay E, Grabherr M, Forche A, Reedy JL, Agrafioti I, Arnaud MB, Bates S, Brown AJ, Brunke S, Costanzo MC, Fitzpatrick DA, de Groot PW, Harris D, Hoyer LL, Hube B, Klis FM, Kodira C, Lennard N, Logue ME, Martin R, Neiman AM, Nikolaou E, Quail MA, Quinn J (2009) Evolution of pathogenicity and sexual reproduction in eight Candida genomes. Nature 459(7247):657-662

64. Lisman J (1989) A mechanism for the Hebb and the anti-Hebb processes underlying learning and memory. Proc Natl Acad Sci U S A 86(23):9574-9578

65. Cummings JA, Mulkey RM, Nicoll RA, Malenka RC (1996) Ca2+ signaling requirements for long-term depression in the hippocampus. Neuron 16 (4):825-833

66. Ismailov I, Kalikulov D, Inoue T, Friedlander MJ (2004) The kinetic profile of intracellular calcium predicts long-term potentiation and long-term depression. J Neurosci 24(44):9847-9861

67. Polydoro M, Dzhala VI, Pooler AM, Nicholls SB, McKinney AP, Sanchez L, Pitstick R, Carlson GA, Staley KJ, Spires-Jones TL, Hyman BT (2013) Soluble pathological tau in the entorhinal cortex leads to presynaptic deficits in an early Alzheimer's disease model. Acta Neuropathol 127:257-270

68. Harris JA, Koyama A, Maeda S, Ho K, Devidze N, Dubal DB, Yu GQ, Masliah E, Mucke L (2012) Human P301L-mutant tau expression in mouse entorhinalhippocampal network causes tau aggregation and presynaptic pathology but no cognitive deficits. PLoS One 7(9):e45881

69. Haapasalo A, Sipola I, Larsson K, Akerman KE, Stoilov P, Stamm S, Wong G, Castren E (2002) Regulation of TRKB surface expression by brain-derived neurotrophic factor and truncated TRKB isoforms. J Biol Chem 277(45):43160-43167

70. Greber BJ, Boehringer D, Leibundgut M, Bieri P, Leitner A, Schmitz N, Aebersold R, Ban N (2014) The complete structure of the large subunit of the mammalian mitochondrial ribosome. Nature 515(7526):283-286

71. Rocher AB, Crimins JL, Amatrudo JM, Kinson MS, Todd-Brown MA, Lewis J, Luebke JI (2010) Structural and functional changes in tau mutant mice neurons are not linked to the presence of NFTs. Exp Neurol 223(2):385-393

\section{Submit your next manuscript to BioMed Central and take full advantage of:}

- Convenient online submission

- Thorough peer review

- No space constraints or color figure charges

- Immediate publication on acceptance

- Inclusion in PubMed, CAS, Scopus and Google Scholar

- Research which is freely available for redistribution

Submit your manuscript at www.biomedcentral.com/submit 